\title{
Structural validation as an input into seismic depth conversion to decrease assigned structural uncertainty
}

Yukitsugu Totake ${ }^{\mathrm{a}, \mathrm{b},{ }^{*},}$ Robert W. H. Butler ${ }^{\mathrm{a}}$, Clare E. Bond ${ }^{\mathrm{a}}$

a Geology and Petroleum Geology, School of Geosciences, University of Aberdeen, Kings College, Aberdeen AB24 3UE, UK

b Technical Resources Unit, Technical Division, INPEX CORPORATION, Tokyo 1076332, Japan

${ }^{*}$ Corresponding author: Tel.: +44 1224 467518. Email address:

yukitsugu.totake@inpex.co.jp (Y. Totake) 


\section{Highlights}

- Kinematic models can verify a range of depth-converted interpretations.

- Area-Depth-Strain (ADS) analysis narrows uncertainty in structural validation.

- Iterative modifications of depth-converted interpretation based on ADS can improve structural interpretation. 


\section{Abstract}

While the interpretation of seismic reflection imagery is powerful and well established for evaluating subsurface structures it is never perfectly accurate. Structural validation techniques are widely used to geometrically test geological interpretations of seismic reflection data. Commonly these techniques are performed on depth sections converted from seismic time-based data using velocity models. Velocity model choices in seismic depth conversion have an impact on the final depth image and hence the structural geometry of interpretations. The impact of these choices in depth conversion on structural validation is rarely examined. Here we explore how multiple versions of a depth section, converted using different velocity models, influence the performance of structural validations for a fold-thrust structure from the deep water Niger Delta. The example illustrates that a range of kinematic models can validate the depth-converted profiles, regardless of the depth conversion choice and are thus poor diagnostic tools. Area-depth-strain (ADS) analysis can constrain the choice both of a kinematic model and the depth conversion, provided the seismic data allow the detachment level and excess areas to be recognised. Incorporation of ADS analysis within an interpretationdepth conversion workflow helps reduce assigned uncertainty in depth conversion, the seismic interpretation, and in the implicit geological model. 


\section{Introduction}

The structure of the crust is illuminated by seismic imagery, yet the interpretation of crustal structure in seismic images is insufficiently constrained. This is due to the nature of a seismic image, which is remotely acquired and displayed in two-way travel time, not depth. Uncertainties in interpretation of seismic imagery have been highlighted in several studies (Bond et al., 2007, 2012; Polson and Curtis, 2010; Torvela and Bond, 2011). The uncertainties arise from several connected factors such as limited data resolution, distortion caused by seismic velocity variations, seismic wipeout at steeply dipping to overturned structures, together with interpreter bias and error. Uncertainty in the interpretation of crustal structure in seismic imagery is a risk to model failure that can result in negative economic, environmental and social consequences.

Structural validation techniques, devised from the concepts of section balancing and geological reasoning developed from the mid-1960s (see Groshong et al., 2012a for a recent review) may be the only practical approach to constrain a range of uncertainty in structural interpretation with the exception of further data collection at additional cost and time. The value of structural validation techniques to geometrically test structural interpretations based on seismic images is well argued elsewhere (Gibbs, 1983; Rowan and Kligfield, 1989; Shaw et al., 2005; Bond et al., 2012; Groshong et al., 2012b; Hughes and Shaw, 2014; Bond, 2015; Eichelberger et al., 2015; Groshong, 2015). In effect these methods test geometric interpretation for internal consistency. When structural validation techniques are applied to seismic data interpretations, such workflows should include time-to-depth conversion because seismic data are processed, and often interpreted, in two-way travel time. These 
seismic time-images inherently have vertical, depth-dependent exaggeration (Stewart, 2012). The domain conversion, time to depth, carries uncertainties due to the absence of robust constraints on the seismic velocity structure. The conversion factors determine the structural geometries observed in depth-converted seismic images. Two questions arise: how great are the impacts of choices of depth conversion on the structural geometries in depth-converted interpretations of seismic images? How effective are validation techniques in determining when depth conversion uncertainty may have induced errors in the interpreted structural geometry?

The purpose of this paper is to explore how structural validation techniques respond to depth conversion uncertainty and how they may be used to inform depth conversion so as to minimise assigned uncertainties in structural interpretation. We believe that this leads to better understanding of limits of structural validations and potential use of the techniques. We depth-convert a seismic profile and its related interpretation of a contractional structure in the deep-water Niger Delta using three different types of velocity model. We then apply three different structural validation approaches to see if these approaches will validate one or more of the depthconverted interpretations. We discuss the performance of the structural validation techniques and outline a methodology for an iterative depth conversion and structural validation workflow, enabling feedback between the domain conversion and the structural validation aspects of seismic image interpretation. The aim is to quantify and reduce assigned uncertainty in depth conversion and hence the associated structural interpretations of seismic images. 


\section{Why is depth conversion so important?}

Seismic reflection images displayed with a vertical scale in two-way travel time present structural geometries that are different from the true geometry due to distortions caused by lateral and vertical changes in seismic velocity (e.g. Etris et al., 2001). This is especially pertinent where subsurface structure and lithology are complex, resulting in significant spatial heterogeneity in seismic velocity (Gray et al., 2001; Bêche et al., 2007). Interpretations of seismic images in the time domain are useful for evaluating large-scale structural style. But when assessments based on the detailed structural geometry of a seismic image interpretation are required, time-todepth conversion is a pre-requisite task (Figure 1).

Depth conversion of seismic imagery is performed using velocity models built from data provided by well check-shot surveys and seismic velocity analyses (e.g. stacking velocities). When velocity data are missing, estimates are sometimes made using regional values or assumptions of velocity vs depth based on inferred rock-types and their compaction state (Figure 1). Velocity models are never precise and have a range of uncertainty that corresponds to errors in the available velocities and their interpolation across the seismic image. Check-shot velocities measured in a well are accurate but sparsely available, sampling a small volume of the rock; while velocities computed from a seismic velocity analysis (that compensate for the effect of receiversource separation on the arrival time, known as "move-out processes") are dense, but have reported errors of $5 \%$ or more (Brown et al., 2004). In general, velocity model uncertainty increases with distance from the well trajectory in which the actual velocities are measured and with distance from the seismic energy source emitting the elastic waves used to construct the seismic image. Uncertainties in the velocity model 
directly relates to the uncertainty in depth conversion, hence the velocity model choice critically influences the structural geometry displayed in depth-converted seismic images.

Studies based on interpretations of depth-converted seismic images, including many structural geology studies, inherit depth-conversion uncertainty (Figure 1). Depth conversion uncertainty, recognised in the geophysics workflow, is rarely considered by interpreters of depth-converted seismic imagery, and is infrequently mentioned in publications. This uncertainty impacts on the basic understanding of structural geometry and deductions of kinematic evolution, for example assessing displacement-distance patterns on faults. Quantifying the impact of depth conversion uncertainty on subsequent analysis of subsurface structures and decision-making in industry could be crucial, for example in predicting the performance of geological models and in predicting subsurface structure before drilling.

\section{Data and methods}

\subsection{Fold-Thrust structure in the deep-water Niger Delta}

We use a seismic profile of a thrust-related anticline forming part of a gravity-driven fold and thrust belt at the toe of the slope in the offshore Niger Delta (Figure 2a). Higgins et al. (2007, 2009) described the structure in detail (Figure 2b), although the whereabouts of the structure in the Niger Delta has not been reported in order to respect the confidentiality of the proprietary seismic data. Their interpretation is based on 3D seismic data and borehole information. The seismically imaged anticline 
extends approximately $30 \mathrm{~km}$, it has a north-south strike and shows oppositely vergent thrusts that trend parallel to the strike (Figure $2 b$ ). The anticline is developed within seismically layered deep-water sand-shale sequences (the Agbada Formation), detached upon a regional over-pressured shale unit (the Akata Formation). Higgins et al. $(2007,2009)$ consider the fold to change vergence along strike as the underlying thrust geometry varies. The anticline verges eastward in its central section, where west-dipping thrusts accompany the folding; and westward in its northern and southern sections where east-dipping thrust faults dominate.

\subsection{Seismic interpretation}

Figure $3 a$ shows the seismic time-image across the crestal part of the anticline. Figure $3 b$ is our interpretation of the profile. In Higgins et al. (2009, their Fig. 15a) the seismic profile is presented only with the horizon h3 label, without a corresponding time interpretation. An adjacent profile, located c. $1 \mathrm{~km}$ south of the interpreted profile, is shown in Higgins et al. (2009) with both the seismic image and interpretation in time (their Fig. 7c and 7c2). This image has been referenced to correlate seismic reflectors interpreted in this study with those of Higgins et al. (2009) (Figure 3c). For correlation purposes the profile is interpreted using the horizon names presented in Higgins et al. (2009). These are: seabed, h10 to h8 in growth strata and h7 to h1 in pre-growth strata. We have interpreted further three horizons, ha, $h \beta$ and hy, between $h 1$ and $h 3$ to increase stratigraphic resolution in the section, these replace the horizon " $h 2$ " in Higgins et al. (2009). 
Seismic reflectors representing multi-layered sandstone-shale alternations are clear and continuous throughout the section except in the anticlinal forelimb in the hanging wall and in the footwall adjacent to the main thrust. Here reflections become ambiguous and discontinuous, potentially due to seismic signal loss introduced by steeply dipping structure and fault shadowing (as described by Fagin, 1996). Growth and pre-growth strata are distinguishable from thickness changes and termination patterns of the seismic reflectors. Growth strata thin toward the anticline crest and onlap pre-growth strata that in turn exhibit a near constant thickness (Figure 3b). Eastward vergence of the asymmetric anticline is clear in the pre-growth package. This anticline broadens at shallower depths within the growth strata. The main thrust fault has a listric geometry and dips west. The fault is interpreted to lie along reflector discontinuities in the pre-growth strata of the fold forelimb and increasingly flattens to a detachment located at a two-way time of c. 6.7 seconds (red arrow in Figure 3b). A back-thrust is recognised in the fold back-limb showing minor offset in the pre-growth strata. Linkage between the observed back-thrust and the main thrust is ambiguous in the seismic image. A small east-dipping thrust fault that lies in the footwall and links with the back-thrust to the south according to Higgins et al. $(2007,2009)$ is inferred from seismic reflectors inclining eastward in the footwall underneath the main thrust fault (Figure 3b). But the fault is not clearly imaged in the seismic profile.

Our reflectors and interpretations have a small geometrical differences from those interpreted by Higgins et al. (2009). These differences in interpretation could be due to possible errors in the image geo-referencing choices and the correlation of seismic reflectors, and could be a source of human-inherent uncertainty in this study. However, the differences are small - estimated to be within $50 \mathrm{~m}$ horizontally and $40 \mathrm{~ms}$ vertically for each horizon and fault interpretation. We estimate maximum errors in scale from 
the adjustment of raster images as $\pm 50 \mathrm{~m}$ and $\pm 10 \mathrm{~ms}$ for horizontal and vertical directions, respectively, together with a maximum uncertainty in seismic reflector correlation of $\pm 30 \mathrm{~ms}$ in two-way travel time.

\subsection{Depth conversion}

\subsubsection{Higgins et al. (2009) depth conversion}

Higgins et al. (2009) have depth-converted their seismic horizons and fault interpretations using interval velocities obtained from a nearby well. Figure 4 shows a comparison of their depth-converted interpretation (Figure $4 a$ ) equivalent to the seismic time-profile in Figure $3 \mathrm{a}$, and our comparable interpretation in two-way time domain (Figure 4b). Structural geometry of seismic horizons in the both profiles are largely comparable. However our fault interpretations differ from those of Higgins et al. (2009) in the following aspects: location of the fault tip of the back-thrust; the linkage between the main thrust fault and the back-thrust; and in the inferred thrust in the footwall. These arise from our choices in picking faults - but their influence on the interpreted horizon geometries, which are important for our purposes here, is minimal. The depth conversion of Higgins et al. (2009) produces relatively unchanged thickness and depth geometry in the shallow section (between seabed and horizon h8) compared to the time-domain profile. On the other hand, the deeper part (below horizon h7) thickens significantly, due to an increase of velocity with depth. Easterlydipping structures in the footwall adjacent to the main fault are transformed from the 
time-image to planar to sub-planar structures in the depth-image. This is a response to pull-up caused by high velocity within the overlying pop-up structure.

Higgins et al (2009) did not specify seismic velocities for their depth conversion. Therefore, in the next section, we create multiple velocity models for converting the seismic time image based on different concepts of the velocity structure. We subsequently search for the best parameters for each velocity model. We assume that the overall depth conversion of Higgins et al. (2009) generally represents the true geometry of the structure.

\subsubsection{Velocity model design}

Three velocity models, used to depth-convert the seismic time-image, have been built based on the structural framework interpretation of the fold-thrust structure (Figure 5). In the simplest scenario, "Velocity Model 1", a constant velocity is uniformly assigned down from the seabed (Figure 5a), to emulate a depth conversion based on an estimate of the average seismic velocity. In "Velocity Model 2", an initial velocity and a gradient are set down from the seabed (Figure $5 b$ ). This creates a depth conversion such as might be obtained from well-derived time-depth curve. The most complex scenario, "Velocity Model 3", consists of three layers under the seabed, each assigned an initial velocity and velocity gradient (Figure 5c), a so-called layer cake velocity model. This type of model is usually built from velocities obtained from boreholes and/or seismic velocity analysis. In this scenario, the topmost sediment layer (V3.1) is equivalent to the growth strata package (between the seabed and horizon h7), the middle sediment layer (V3.2) is the upper pre-growth strata (between 
h7 and h3) and the lowermost layer (V3.3) is the lower pre-growth strata (below horizon h3). For the Velocity Model 3, we define such layering while considering velocity changes that are assessed from comparisons of thicknesses in time and depth (Figure 4).

The designed variety in the three velocity model scenarios produces a conceivable range of depth conversion uncertainty for subsurface structures lying in a shallow section of a clastic sedimentary basin (c. down to $3 \sim 4 \mathrm{~s}$ or $4 \sim 5 \mathrm{~km}$ below sediment surface).

\subsubsection{Velocity parameters and profiles}

We assume that the depth conversion of Higgins et al. (2009) reasonably represents the true geometry of the structure, as it is constrained by a borehole data. We inversely seek the best velocity parameters, namely initial velocities at layer tops and vertical velocity gradients, in order to obtain depth-profiles close to that of Higgins et al. (2009).

We calculate seismic average velocity for the uppermost layer (V0 in Figure 5), the seawater section, by averaging velocities calculated from two-way travel times and depths measured along the horizon seabed at every $500 \mathrm{~m}$ horizontal interval. We compute velocity parameters for layers below seabed (V1-V3.3) by minimising the sum of squares of depth-differences measured at a horizontal interval of $500 \mathrm{~m}$ between depth-converted interpretations in this study and comparable depth interpretations (seabed, h10-h3 and h1) in the interpretation of Higgins et al. (2009) (Figure 4a). For this parameter search, we apply an optimization function "fminsearch" in the MATLAB 
Optimization Toolbox ${ }^{\mathrm{TM}}$. Initial guesses of layer-top velocity(s) and velocity gradient(s) for each velocity model are given in ranges of $1.5-3.0 \mathrm{~km} / \mathrm{s}$ and $0.0-0.5 \mathrm{~s}^{-1}$, respectively. To avoid the parameter search stopping at local minima, we run at least ten searches with different parameters of initial guess.

Table 1 summarises velocity parameters computed for three depth-conversion scenarios. The velocity for the uppermost layer (V0) presents the typical value for seawater $(1.5 \mathrm{~km} / \mathrm{s})$. Velocities for sub-seabed layers (V1-V3.3) are consistent with unconsolidated to moderately compacted siliciclastics (Veeken and Moerken, 2013). We obtained the negative velocity gradient of $-0.12 \mathrm{~s}^{-1}$ for the lowermost layer (V3.3) in Velocity Model 3. This could indicate an overpressure zone lying above the decollement surface, as discussed for other parts of the Niger Delta by Cobbold et al (2009). Further discussion of the significance of overpressure detection is beyond the study scope here.

Finally, average velocity profiles calculated from the interval velocities are used to convert the seismic profile and our interpretation to depth (Figure 6). Velocity Model 1 produces higher average velocity in the shallow section (above h7) and lower average velocity in the deep section (below h1) (Figure 6a), than the other two models (Figure $6 b$ and $6 c$ ), because it uses a single mean interval velocity. Velocity Model 2 generates a more vertically varied average velocity compared to Velocity Model 1 , without lateral velocity change (Figure $6 \mathrm{~b}$ ). Velocity Model 3 produces a velocity distribution that corresponds to the structure of the fold-thrust system (Figure 6c); pregrowth strata with high velocity are transported over the footwall and vertically repeated by the main thrust in the model. The average velocity for Velocity Model 3 is smoothed to avoid artefacts caused by abrupt velocity changes between the velocity layers and fault blocks. 


\subsubsection{Difference in depth conversion results}

The difference in the velocity model alters the structural geometry of the depthconverted interpretation and the seismic image (Figure 7). The depth-profile converted by Velocity Model 1 (Figure 7a) displays thickening of the shallow section (between h10 and h8) and thinning of the deeper section (below h7) compared to the other two depth-converted profiles (Figure 7b and 7c), due to use of a constant interval velocity with depth. These thickness differences are obvious from measurements of vertical thickness between horizons ( $T_{v}$ in Figure 8a) as shown in Figure 8b. Thinner packages below $\mathrm{h} 7$ result in relatively gentle dips of thrust faults and the fold relief, and a shallow detachment level in the profile; the main thrust dips $38^{\circ}$ westward in the middle of the fault trajectory, the fold back-limb dips $12^{\circ}$ westward at horizon $\mathrm{h} 4$ and the detachment is recognised at a depth of $5.8 \mathrm{~km}$ (Figure 7a). Corresponding measurements are $45^{\circ}$, 14-15 ${ }^{\circ}$ and 6.1-6.2 $\mathrm{km}$ in the other depth-converted profiles (Figure $7 \mathrm{~b}$ and $7 \mathrm{c}$ ). In contrast, Velocity Model 2 dramatically thickens the deeper section below $\mathrm{h} 7$ and accentuates the anticline relief in the depth-profile (Figure $7 \mathrm{~b}$ and $8 \mathrm{~b}$ ); consequently the profile produces the greatest structural relief (Figure 8c), measured vertically from the top of anticline to the base of the syncline ( $h$ in Figure 8a). Velocity Model 3 produces a visually similar depth-profile to that of Velocity Model 2 (Figure 7c), but the pre-growth structure is less deformed as Figure 8c shows relatively low reliefs of the structure below h7, compared to those of Velocity Model 2. This is due to thickening of the hinge zone in the upper pre-growth section (between h7 and h5); as the velocity 
model, by design, uplifts a higher velocity body through thrust repetition of the deeper (high velocity layer) in the core of the fold.

Bed length ( $L$ in Figure 8a), which is often used to quantify values of extension/shortening in comparison to section length, shows little difference among the depth conversion outcomes (Figure 8d). The maximum difference in bed length is $71 \mathrm{~m}$ at horizon h3 between depth conversions using Velocity Model 1 and 2 . This value is less than $1 \%$ of the total section length of $8 \mathrm{~km}$ that embraces the entire deformation zone. Such a small impact of the different depth conversions on the bed length is explained by sub-horizontal structures dominating the section. Apparent bed length differences would increase in response to vertical exaggeration effects introduced by depth conversion as dips become steeper (Stewart, 2012).

Plotting displacement-distance relationships along fault is an established approach for predicting a fault tip position and structural style (Williams and Chapman, 1983; Hughes and Shaw, 2014). For our case study, regardless, of the velocity model used for depth conversions (Figure 8e), displacement-distance plots are similar. A near constant displacement region occurs between $h 1$ and $h \beta$, followed by near-linear decrease of displacement toward the fault tip above $\mathrm{h} \beta$. Velocity Model 1 produces a displacement profile shifted to the left on the displacement-distance graph from those of Velocity Models 2 and 3. This is attributed to relatively thin packages at depth in the Velocity Model 1 profile, leading to smaller displacements ( $D$ in Figure $8 a$ ) and a shorter fault distance ( $d$ in Figure 8a) in the deeper section. Nevertheless, these displacement-distance relationships are, for our case study, relatively insensitive to the adopted velocity model.

Our depth-converted profiles are compared to the equivalent depth interpretation of Higgins et al. (2009, their Fig. 15b) for plausibility (Figure 9). All the depth-profiles 
converted in this study display uplift of horizon h1 beneath the main thrust (upper panel in Figure 9a-c), which are not observed in the original Higgins et al. (2009) depth interpretation. These uplifts, often referred to as pull-up structures, are thought to be the product of differences in the geometry of time interpretations and the velocity assignments for depth conversion. The Velocity Model 1 depth-profile marks a shallower detachment level than that of Higgins et al. (2009) (Figure 9a), whilst the other two velocity models present similar depths of the detachment to the Higgins et al (2009) depth-profile. We cross-plot measured depths for the horizons of Higgins et al. (2009) against the comparable horizons derived from our depth conversions (lower panel in Figure 9a-c). Horizon depths are measured at a horizontal interval of $500 \mathrm{~m}$ and are used to calculate statistic $R^{2}$ values, called coefficient of determination, defined by:

$R^{2}=1-\frac{\sum_{i}\left(y_{i}-x\right)^{2}}{\sum_{i}\left(y_{i}-\bar{y}\right)}$

where $y_{i}$ is depth measurements for Higgins et al. (2009) depth horizons, $\bar{y}$ is the mean of $y_{i}$, and $x_{i}$ is depth measurements for the horizons in this study. Here the closer $R^{2}$ is to 1 represents a better fit of depth-converted horizons in this study to depth horizons of Higgins et al. (2009). These plots and statistics allow us to assess the realism of each velocity model, assuming that the Higgins et al. (2009) depth conversion, based on velocities determined in a nearby well, best represents the true seismic velocities of the rocks imaged. As expected, our depth conversions present better correlation, closer $\mathrm{R}^{2}$ to 1 , with increase in the degree of complexity of the velocity model; e.g. Velocity Model 3 has the highest $R^{2}$ of 0.996 - the best fit (Figure 9c). But all velocity models have an $\mathrm{R}^{2}$ greater than 0.96 , meaning at least 96 percent 
of the Higgins et al. (2009) depth interpretation is predictable from depth conversions using these velocity models. Given these $\mathrm{R}^{2}$ values, all the velocity models are assumed to be plausible for depth conversions that may have been undertaken if nearby well data was not available.

\subsection{Structural validation techniques}

The three depth-converted versions of the seismic profile and interpretations are structurally validated using three approaches. Firstly, we carry out structural restoration and forward modelling using iterative manual manipulation of the modelling parameters to visually fit the observed fold-thrust structure. Secondly, 'inverse trishear modelling' above the listric fault (Cardozo and Brandenburg, 2014) is applied to automatically match the structure. Finally, the area-depth-strain (ADS) method (Epard and Groshong, 1993; Groshong and Epard, 1994; Groshong et al., 2012b) is applied to test the structural geometry of the depth interpretations independently of kinematic assumptions.

\subsubsection{Restoration and forward modelling}

Various kinematic models have been produced to account for fault-related folding since the early 1980s (see Brandes and Tanner, 2013 for a recent review). Selecting the 'correct' kinematic model, and associated parameters, is key for validating a structure or assessing a structural evolution history. The seismic profile displays the 
listric fault trajectory of the main thrust that together with downwards steepening forelimbs and gentle back-limbs in the hanging wall, and synclines in the footwall. These characteristics accord with outputs from the trishear algorithm when applied to listric reverse faults (Pei et al., 2014). A fault displacement-distance pattern with an upwards decrease of displacement against fault distance above horizon hy (Figure 8e), indicates that fault-propagation fold kinematics account for the structure (Hughes and Shaw, 2014). A component of fault-bend folding is implied by the near constant displacement for intervals between $\mathrm{h} 1$ and $\mathrm{h} \beta$. However, this interval is a small part of the whole profile. Therefore we choose to model the structure using trishear faultpropagation-folding.

We use the program Move, which allows us to perform the restoration and forward modelling using a trishear algorithm for a listric fault. We determine trishear parameters (such as fault slip, trishear angle and propagation-to-slip ratio) to restore the fold-thrust structure for the growth and pre-growth strata, using the program function 'Construct Horizon from Fault'. This automatically updates geometries of horizon prediction as trishear parameters and the fault geometry are changed. To constrain the model parameters, offset measurements at horizon h1 along the trajectory of the main thrust $(1.02 \mathrm{~km}, 1.09 \mathrm{~km}$, and $1.06 \mathrm{~km}$ for the section produced by Velocity Model 1, 2, and 3, respectively) are regarded as minimum fault displacements. Propagation-to-slip ratios of 2.0 to 4.0 are set as a parameter range, with the maximum fault displacement of $1.50 \mathrm{~km}$ and the fault tip located between horizons $\mathrm{h} 7$ and h9. The back-thrust recognised in the fold back-limb and the small east-dipping thrust inferred in the footwall are not included in the modelling due to their minor offsets (less than $110 \mathrm{~m}$ ). 
After restoration of the movement on the main thrust, a remnant of anticline amplification is restored using the detachment fold algorithm to achieve sub-horizontal pre-deformation strata. These restoration steps kinematically agree with earlier folding before the faulting, proposed by Higgins et al. (2009) as a possible process of thrust initiation and supported by their observations at the fold termination area. However, other combinations of deformation can also yield satisfactory restorations, such as a movement on another thrust fault in the footwall (Pei et al., 2014).

An initial template of the retro-deformed horizons is constructed by linearly regressing the geometry of restored beds. These are then used as a template for forward modelling by applying the kinematic parameters determined by the restoration. The geometry of the forward modelled horizons are cross-checked for fit against the depth-converted seismic image. Through these steps, geometrically- and kinematically-balanced interpretations are achieved, the kinematics of the evolution of the structure are obtained, and the validity of the interpretation is checked.

Compaction effects are not taken into account in this study. We assume that most of the compaction in the pre-growth package occurred as the deformation initiated. Lateral and vertical compaction in such deep water sediments is expected to be significant, with implications for structural validation of deep water systems (e.g. Butler and Paton, 2010). Although, some authors suggest that heterogeneity in compaction effects are not crucial for structural validation (Eichelberger et al., 2015), evidence from the Agbada Formation in the Niger Delta suggests significant implications for seismic velocities in differentially compacted strata. Here our focus is on a combined workflow for structural interpretation/validation and depth conversion, exemplified through scenarios, using the fold-thrust structure as a case study, rather than a desire to best model the structure. Consequently we neglect the effects of compaction here. 
The results of the restoration and forward modelling, using a combined detachment fold and trishear fault-propagation folding approach, are shown in Figure 10. The predicted kinematics associated with the structure in three depth-converted profiles are summarised in Table 2. The Velocity Model 1 depth-profile requires a greater amount of total fault slip of $1.32 \mathrm{~km}(1.30 \mathrm{~km}$ for trishear fault propagation-folding and $15 \mathrm{~m}$ for detachment fold), along with a significant amount of shear (shear angle of $30^{\circ}$ ), compared with the other two depth-profiles (Figure 10a and Table 2). This high value for required fault slip is attributed to the gently dipping structure in the depthprofile of Velocity Model 1. Velocity Model 2 and 3 are kinematically modelled with broadly similar parameters. We measure distance of mismatch between our forward models and the depth-converted interpretations within the program Move. All seismic depth-profiles can be forward modelled, with a maximum deviation from the original horizon interpretations of $\sim 200 \mathrm{~m}$. Note that differences in the employed velocity model do not introduce meaningful changes in the geometrical fit between the horizon geometry predicted by the forward modelling and the depth-converted interpretation. The forward modelled horizon geometries commonly show the largest differences, c. 150-200 m, with the interpretation on the forelimb of the structure in the fold core, on the back-limb and at the syncline in the footwall adjacent to the main thrust. These mismatches are potentially due to greater complexity in the structure than we have modelled here. For example, movements of fault splays or oppositely vergent thrusts have not been included in the trishear and fault-propagation fold modelling. Furthermore trishear parameters (trishear angle, $\mathrm{P} / \mathrm{S}$ ratio and shear angle) may have varied as the fault propagated while we have assumed that they remained constant. Alternatively, mismatches between forward model outputs and the seismic structure may arise from interpretation error, especially in areas of poor image resolution. 
However, causes of such inconsistencies between the model and the interpretation are inconclusive as borehole data such as dip meter and stratigraphic information, efficiently used by Kostenko et al. (2008) to constrain their model, were not available for our study.

Restored beds of the pre-growth section for a state before the trishear faultpropagation-folding present broad and low-amplitude folding in all the depth-profiles (Figure 10b). These remnant folds can be emulated or restored by detachment fold models with small displacements of $10-15 \mathrm{~m}$ and low-angle fold limbs of $3-7^{\circ}$. Differences in the model parameters by the choice of depth conversion are not definitive. The restored geometry of the pre-growth section can be effectively restored to horizontal before the folding and faulting regardless of the depth-profiles we have adopted (Figure 10c). Likewise all the restorations yield near-constant thicknesses for the pre-growth strata.

\subsubsection{Inverse trishear modelling}

In trishear modelling, as the triangular zone of deformation propagates through the rock material, the algorithm updates the structural geometry for each deformation increment (Erslev, 1991; Allmendinger, 1998). In contrast, other algorithms such as kink-type fault-propagation, fault-bend and detachment folding can be determined graphically based on fault displacement and geometry. Rather than the two parameters (fault displacement and geometry) that describe the kink-type models, trishear has six parameters. These are: the $x$ and $y$ coordinates of the fault tip, the ramp angle (fault dip), the fault propagation to slip (P/S) ratio, the apical angle of the 
triangular zone of deformation, and the fault slip (Allmendinger, 1998). As opposed to the kink-type fault-related fold models where the P/S is dictated by the algorithm, the $\mathrm{P} / \mathrm{S}$ in trishear is an input (Allmendinger et al., 2012, chapter 11). This feature, together with the other parameters, provides flexibility for modelling a wide diversity of foldthrust geometries. Conversely trishear provides challenges for manually determining the parameter set that best matches a given structure (section 3.4.1). Optimized inverse trishear modelling is an efficient technique to determine a range of best-fitmodels (range of parameter combinations), rather than providing a single model (Cardozo and Aanonsen, 2009; Cardozo et al., 2011).

We program the inverse trishear model for a listric fault in MATLAB according to the methodology of Cardozo and Brandenburg (2014) using global, simulated annealing optimization. The modelling is used to find the trishear models that best fit our depth-converted interpretations. In this approach, the geometry of the main thrust fault is given as a circular arc with a centre and radius of curvature (CC and RC respectively) and maximum central angle ( $\theta_{\max }$, see Fig. 1 of Cardozo and Brandenburg, 2014 for further details). The result is that the fault steepens as it propagates upwards.

In the restoration, the fault tip location moves backwards at a slip increment of $5 \mathrm{~m}$ along the fault trajectory while restoring the deformation in the hanging wall and within the trishear zone. Geometrical agreement between the final restored state and an initial template are measured by an objective function $\left(f_{\mathrm{obj}}\right)$. This calculates the sum of squares of differences between the template and the restoration. We define the initial template using a linear regression of restored bed geometry, in contrast to the Gaussian function used to emulate possible pre-kinematic folding by Cardozo and Brandenburg (2014). In this study, several runs of inversion trishear modelling with 
Gaussian-function templates have shown that a maximum amplitude for the detachment fold amplitude of less than $30 \mathrm{~m}$ resulted in smaller values of the objective function. This low value for fold amplitude in the pre-kinematic geometry suggests that a horizontal bed-template can be used as the target for inverse trishear modelling, without resulting in significant errors. Our program minimizes the value of the objective function by searching parameters in fault geometry $\left(\mathrm{CC}, \mathrm{RC}\right.$ and $\left.\theta_{\max }\right)$ and trishear kinematics (fault propagation-slip ratio, trishear angle, fault slip, and shear angle). 'Annealing' parameters are regularly used to avoid trapping in local minima in solution space. Parameters are searched within a constrained parameter space with the user determining the lower and upper limits. The parameter inputs into this study are summarised in Table 3 . We use horizon h5, the most clearly imaged and continuous reflector in the pre-growth strata, as the horizon to be matched in the inverse trishear modelling. We then apply the searched parameters to all other pre-growth horizons to predict the structure. Best-fit fault slips are searched for growth horizons (h8, h9 and h10) using the same fault geometry and the kinematics determined for matching horizon h5. Parameter searching is run for 10,000 iterations, with annealing after every 100 iterations. As in the restoration and forward modelling, the effects of compaction and the minor faults are not incorporated into the model.

The best-fit trishear model, with the lowest $f_{\mathrm{obj}}$, is shown in Figure 11a. The models show reasonable fit with the seismic profile and the interpretations for all depth conversion scenarios, regardless of the velocity model used. Similar to the results of the restoration and forward modelling, relatively large deviations from the interpretations are observed on the fold forelimbs in the hanging wall and the synclines in the footwall. But without further constraints such as well data, these inconsistencies are inconclusive for judging if the interpretation or the model prediction require 
modifications. The best-fit fault slips for growth strata (h8, h9 and h10) are 1.12, 0.42 and $0.16 \mathrm{~km}$ for the depth-profile of Velocity Model $1,0.74,0.28$ and $0.10 \mathrm{~km}$ for that of Velocity Model 2, and $0.75,0.26$ and $0.09 \mathrm{~km}$ for that of Velocity Model 3.

Our program provides a range of the model parameters that best fit the depthconverted interpretation with low $f_{o b j}(<0.3)$ (Figure 11b). Low $f_{o b j}$ trishear models effectively mimic the geometry of pre-growth beds. However a number of unreliable models, with the thrust having propagated through the growth strata above horizon h9, are included - particularly for depth-profiles converted using Velocity Model 1 (left in Figure 11b) and Velocity Model 2 (middle in Figure 11b). Restored geometries of those models (Figure 11c) show near constant bed thicknesses of the pre-growth section for the all depth-profiles. These are similar to the geometries of retro-deformed beds obtained manually through the restoration and forward modelling (Figure 10c).

Distributions of model parameters commonly show that the parameter spaces for $\mathrm{P} / \mathrm{S}$, trishear angle and shear angle are relatively broad while fault slip has a rather narrow distribution (Figure 11d). The depth-profile for Velocity Model 1 produces a particularly broad spread for P/S, trishear angle and shear angle (left in Figure 11d), compared with the other two depth-converted profiles (middle and right in Figure 11). However parameter distributions become comparable if only those trishear models associated with reasonable thrust geometries (shown by grey bars in Figure 11d) are considered. In general, Velocity Model 1 produces the greatest fault slip, followed by Velocity Model 2 and then 3, as observed in the restoration and forward modelling. The number of models with inconsistent fault geometries (shown by white bars in Figure 11d) are the largest for depth-section for Velocity Model 1 ( $N=136,63.0 \%$ of Low $f_{o b j}$ models), followed by Velocity Model $2\left(\mathrm{~N}=32,49.2 \%\right.$ of Low $f_{o b j}$ models). Models for the depth-section of Velocity Model 3 perform better with the smallest 
number of unreliable models ( $N=28,25.0 \%$ of Low $f_{o b j}$ models). Trishear models predicted through the manual restoration and forward modelling (shown by asterisks in Figure $11 d$ ) are largely within the range of low $f_{o b j}$ models, but rarely hit the lowest $f_{o b j}$ model. This demonstrates a manually obtained best-fit kinematic model is but one of a number of possible solutions.

\subsubsection{Area-Depth-Strain analysis}

Area-depth-strain (ADS) analysis (Epard and Groshong, 1993; Groshong and Epard, 1994) is a non-kinematic technique for predicting fault displacement and detachment depth. These are derived from measurements of excess area and the depth of multiple horizons in a structure. Excess-area diagrams, plotting measured excess area of multiple beds against the depth from a reference line, give boundary displacements represented by the inverse slope. The detachment depth is indicated by the zero-area intercept for a fault-propagation fold structure (Schlische et al., 2014; Groshong, 2015; Eichelberger et al., 2015). Sub-seismic layer-parallel strain (LPS) can also be measured from the boundary displacements, bed lengths and section lengths (e.g. see equation 5 in Groshong et al., 2012b). Positive values indicate layer extension, while negative ones indicate layer contraction. The diagram facilitates easy distinction of the pre-growth and growth strata from the change in slope of the plotted line (Schlische et al., 2014). The structural style can be classified from the line pattern and the area-depth relationship (Groshong, 2015). A balanced interpretation within a pre-growth strata results in well-defined lines on the ADS diagram. In these instances the predicted detachment depth can be used in conjunction with the seismic reflection image as a tool to quality check interpretations. 
To perform ADS analysis in this study, excess areas are measured for every bed within the program Move for each depth conversion scenario and plotted (Figure 12). The depth of the excess area for each horizon is read in the middle of the section (see location of white triangles on Figure 12a-c). The displacements and detachment levels have been computed from a one-dimensionally regressed line of the area-depth plots for the pre-growth interval. We calculate displacements for the growth strata from slopes between the area-zero detachment depth and area-depth points of each growth bed (Schlische et al., 2014; Groshong, 2015).

The ADS analysis from the study is given in Figure 12d-f. Interpretations for each depth conversion scenario show distinct differences in the area-depth relationship for the growth and pre-growth sections. Excess area in the growth package decreases upward, while the excess area in the pre-growth section decreases downward. Areadepth relationships in the pre-growth section show nearly linear trends for all the depth conversion scenarios, with high $\mathrm{R}^{2}$ values of 0.9915 to 0.9977 . Thus, interpretations for all depth conversion scenarios are regarded as reasonably balanced.

Kinematic predictions given by ADS analysis challenge either the interpretation or the depth conversion. Firstly, for depth sections produced by Velocity Model 1 and 2, the area-depth graph indicates significantly deeper detachments, namely $6.0 \mathrm{~km}$ and $6.7 \mathrm{~km}$ (Figure 12d and 12e), than those picked in seismic images, (5.8 $\mathrm{km}$ and 6.2 $\mathrm{km}$ respectively; Figure $12 \mathrm{a}$ and $12 \mathrm{~b})$. These detachment mismatches $(0.2$ to $0.5 \mathrm{~km})$ indicate errors in the interpretation or in the depth conversion (Groshong, 2015). Velocity Model 3 gives a detachment level that conforms to the detachment interpreted in the seismic image at a depth of $6.2 \mathrm{~km}$ (Figure 12c and 12f). Thus this profile is more geologically reasonable compared with those obtained by the less elaborate velocity models. 
The area-depth-profile for depth-profile derived from Velocity Model 1 shows a fault displacement of $1.33 \mathrm{~km}$ (Figure 12d). In contrast the depth-profiles from Velocity Model 2 and 3 show smaller displacements $(0.93 \mathrm{~km}$ and $0.96 \mathrm{~km}$, respectively; Figure $12 \mathrm{e}$ and 12f). Correspondingly, Velocity Model 1 produces significantly higher LPS values; particularly in the section between h5 and h8 with LPS values of greater than $-7 \%$ (Figure 12a). According to Groshong (2015) this value exceeds a tolerable limit for LPS where deformation is accommodated at a grain-scale. In contrast Velocity Model 2 and 3 depth sections show positive LPS values between hy and h1 (Figure $12 \mathrm{~b}$ and $12 \mathrm{c})$. These positive LPS values, indicating extensions, are attributed to smaller boundary displacement predicted by ADS analysis than the maximum shortening value calculated from bed lengths; ADS analysis predicts displacements of $0.93 \mathrm{~km}$ and $0.96 \mathrm{~km}$ while bed lengths indicate shortening amounts of $1.16 \mathrm{~km}$ and $1.13 \mathrm{~km}$, for the depth-profiles of Velocity Model 2 and 3, respectively. The interpretations may be modified by shifting area-depth points for the upper pre-growth strata horizons (e.g. h5 and/or h6) to the right and the lower pre-growth horizons (e.g. h1) to the left in these profiles so that ADS analysis would give greater boundary displacement and more reasonable LPS strains. Such modifications can be made by reviewing the interpretation and the depth conversion.

Summarizing, the ADS analysis shows that the depth-profile produced by Velocity Model 3 is the most satisfactory, because the interpretation is balanced and the depth conversion is geologically reasonable. Although minor modifications can be advised to obtain more favourable LPS values, extensive changes are not required for this depth-profile. Conversely, ADS analysis shows that Velocity Model 1 and 2 depthprofiles are geologically unacceptable. To obtain a prediction in which the detachment level and LPS values well-match the seismic image, modifications of the interpretation 
appear to be not enough for these depth-profiles - a revision of the depth conversion seems crucial.

\section{Discussion}

\subsection{Impact of depth conversion on geometrical assessment}

We have shown that in this study the designed range of depth conversion, or depth conversion uncertainty led to variation in both the structural geometry of the depthconverted profile and its interpretation. This uncertainty in depth conversion is a recurrent issue for understanding subsurface structure, especially for hydrocarbon exploration in areas where no nearby well data is available. We have observed that thickness and dip of stratigraphic units are sensitive to differences in seismic velocity used in interpretations, especially at deeper levels of the section. Consequently different interpretations show variations in the elevation of horizons of up to $200 \mathrm{~m}$ and place the detachment at depths that vary by c. $500 \mathrm{~m}$. These geometrical changes would have a big impact on an estimation of hydrocarbon reserves, as these measurements control evaluations of maximum hydrocarbon column height and a maturity of a source rock often coexisting with a detachment zone (Zanella et al., 2014). In contrast, bed length and fault displacement-distance patterns are reasonably insensitive to the modelled depth conversion scenarios. Hence, an assessment of kinematic evolution models using these tools may still be useful even when the depth conversion is uncertain. However, further uncertainties are likely to arise in examples 
that include significant lengths of steeply-dipping strata because parts of seismic sections are especially sensitive to vertical exaggeration (e.g. Stewart, 2012).

\subsection{Performance of structural validation against depth conversion uncertainty}

Structural validation techniques might be expected to have discriminated between the three velocity models adopted in our study. Yet all versions of the depth-converted interpretation have been kinematically and geometrically modelled within deviations of c. $200 \mathrm{~m}$ from the interpretation. In other words, the possible variations in the structural geometry of the interpretation under the depth conversion uncertainties modelled can all be 'validated' by kinematic modelling, as long as some mismatches between the prediction and the interpretation are tolerated. Inverse trishear modelling is also similarly insensitive. A range of trishear models 'fit' the structure regardless of the depth conversion choice. It is the inherent flexibility of the kinematic models that allows them to validate each of the depth-converted interpretations. Adjustments of model parameters and fault geometry during the workflow enable the 'match' of diverse structures; Some kinematic models even have enough flexibility to mimic a vertically exaggerated structure geometry (Stewart, 2012). Tolerating deviations between forward model outputs from the seismic interpretation further widens the window of model acceptance. While significant deviations might be regarded as indicating geologically and geometrically unreasonable interpretations, further data may be

needed to evaluate their causes. Even if additional constraints are obtained, accomplishment of a structural validation without any deviation from the interpretation is ultimately challenging: the idealised kinematic models are too simplified (Torvela 
and Bond, 2011). Therefore interpreters embarking on such workflows would be advised to state the requirements and tolerances of the model outputs.

Statistics of kinematic parameters obtained through computerized inverse kinematic modelling may help for narrowing assessed uncertainty in depth. Cardozo and Aanonsen (2006) applied the inverse trishear modelling to a thousand synthetic interpretations that were randomly generated from a best-fit trishear model for a foldthrust structure. These realisations tolerated a maximum error of $10 \%$ in depth conversion. Based on probabilistic distributions of best-fit trishear parameters searched for within the synthetic data, they quantified a range of uncertainties that the depth conversion may cause in the best-fit model parameters. This approach is called the randomized maximum likelihood $(\mathrm{RML})$ method. If a dataset or geological context exclude part of the range in trishear parameters obtained by the RML technique, the assessed uncertainty range in the depth conversion could be reduced.

Some of the best-fit trishear models searched for by the inverse trishear modelling in this study, yield thrust geometries that propagate through the growth strata and are thus geologically unreasonable (Figure 11b). Identifying these misfits may inform probabilistic robustness of the depth conversion. The ratio of unreliable trishear models to the total number of low $f_{o b j}(<0.3)$ model, or the search probability of geologically unreasonable model, is in inverse proportion to the similarity $\left(\mathrm{R}^{2}\right)$ of our depth-converted interpretation to that of Higgins et al. (2009). Given that the Higgins et al. (2009) depth interpretation is constrained by nearby borehole data, this ratio of unrealistic trishear models may imply a likelihood of geological incompatibility of the depth conversion; Velocity Model 1 has the highest risk of geological mismatch in the depth conversion while Velocity Model 3 has the lowest. However, this judgment on the compatibility of depth conversions remains inconclusive - the approach also 
provides models that satisfy the structural geometry of the depth-converted interpretation for the same depth-profiles.

The response of ADS analysis to the depth conversions is the most sensitive of the structural validation techniques applied here. The detachment level given by ADS analysis significantly varies according to the choice of depth conversion and highlights inconsistency in the depth-converted profile and interpretation. LPS values calculated by ADS analysis also inform judgements of the interpretation validity. Modifications of the interpretation for obtaining a compatible detachment level and LPS values with the seismic image are more difficult for the depth conversion scenarios using Velocity Model 1 and 2. Therefore, a review of depth conversion, or velocity model parameters, is recommended. Similar assumptions of seismic velocities to both Velocity Model 1 and 2 are frequently introduced in a large number of structural geology studies (e.g. assumption of seismic average velocity). While kinematic model approaches would apparently validate such velocity assumptions, the ADS analysis is highly sensitive to those velocity choices. Therefore the ADS analysis is more useful to assess if the depth-converted profile is geologically reasonable.

\subsection{Implications for depth conversion and structural validation workflows}

Structural validations using kinematic models contribute to ensuring geologically reasonable interpretations, or highlight inconsistencies in seismic interpretation for a given depth-converted seismic profile. But uncertainty arising from the choice of depth conversion and kinematic model parameter settings still remains even in validated interpretations. Kinematic models can be adapted to 'fit' when there are few available 
data to constrain the models. Use of ADS analysis can constrain this uncertainty. We have shown that outcomes of ADS analysis are meaningfully sensitive to the choice of depth conversion compared with those of kinematic methods. Hence ADS analysis can inform geological validity of depth conversions. The approach also independently constrains structural validations using kinematic models because it is non-kinematic.

We propose a combined workflow for depth conversion and structural validation of interpretations of fold-thrusts imaged by seismic profiles (Figure 13). Commonly a seismic interpretation is finalized through time-domain interpretation followed by a time-to-depth conversion. As shown in Figure 1, the input interpretation is rarely reexamined. In our workflow, we propose that the depth conversion is followed by ADS analysis to check validity of both of the input interpretation and of the depth conversion. Given that the ADS analysis can be performed quickly, it is suitable for testing preliminary products of interpretation and depth conversion, such as a few seismic markers on representative seismic sections. Once the test using ADS analysis is satisfied, with subsequent modification of interpretation and depth conversion, structural validation using kinematic models and infill interpretation can be implemented to verify the depth interpretation in detail and to analyse kinematic evolution. Execution of ADS analysis prior to structural validation using kinematic models gives constraints on the kinematic model parameters increasing the efficiency of kinematic forward modelling.

ADS analysis may prove useful for the improvement of seismic imaging. A number of authors (e.g. Jardin et al., 2007) have argued that incorporating interpreted geological models into seismic data processing will improve seismic imaging. ADS analysis can quantitatively test the validity of geological concepts and highlight problems in interpretations and depth conversions. Updating seismic velocity analysis 
in accordance with feedback from ADS analysis of rough interpretations on fast-track seismic data is expected to be highly effective.

We note that such uses of ADS analysis are recommended on condition that a seismic image allows both the excess area and the detachment level to be determined. For examples where seismic images contain substantial areas of wipe-out zones caused by steep-to-overturned fold limbs or gas chimneys, using ADS analysis in conjunction with kinematic models may be a better approach. In these cases our suggested workflow in Figure 13 could be adapted depending on the quality of seismic data.

\section{Conclusions}

Interpretation based on seismic reflection imagery builds on uncertainty arising from limited seismic data resolution, depth conversion error and human bias. Structural validation techniques have been regarded as one of the most practical approaches to constrain such uncertainty by excluding geologically inconsistent interpretation geometry. Our work suggests structural validations using kinematic models are rather too adaptable for the variation in the structural geometry of depthconverted interpretations, particularly when hard data such as well penetrations for constraining the geometry of subsurface structure are missing. Hence, they cannot dramatically reduce assigned uncertainty in depth-converted interpretations where the seismic reflection imagery is good. This is due to the flexibility of kinematic models introduced by adjustable parameters and fault geometries. Compared to kinematic approaches, the area-depth-strain (ADS) analysis is highly sensitive to possible 
variations in the structural geometry of depth-converted interpretations, and distinctively highlights inconsistency in the depth-converted profile.

The ADS analysis can be used to test the validity of depth conversion choice and the efficacy of kinematic models in determining balanced structures, by iterative modification of the interpretation and depth conversion, even without further constraining data (e.g. borehole information). We expect that assigned uncertainty in depth conversion and interpretation can be efficiently reduced through application of the ADS analysis at initial stage of seismic interpretation, along with trial depth conversions to produce more robust geological subsurface models. ADS analysis also has the potential to improve seismic imaging if the approach is incorporated in seismic velocity analysis, by testing the reflector geometry. ADS analysis can be used if a seismic image quality allows recognition of the excess area and the detachment level. Depending on a seismic image quality, a use of ADS analysis in combination with kinematic models is recommended.

\section{Acknowledgements}

This study is based on PhD research project funded by INPEX CORPORATION at University of Aberdeen. Seismic images for this study were taken from the Higgins et al. (2009), through the courtesy of CGG (formerly CGG Veritas). Further examples are available through the Virtual Seismic Atlas (www.seismicatlas.org). Restoration and forward modelling and measurements for the area-depth-strain analysis were performed in Move 2016.1 by Midland Valley made available through academic partnership. Trishear inverse modelling was programmed referring to MATLAB scripts 
publicized on Allmendinger et al. (2012, chapter 11) and Nester Cardozo's website (http://www.ux.uis.no/ nestor/work/programs.html) and implemented in MATLAB 2015b. Finally we thank Nester Cardozo and Richard Groshong for valuable comments that significantly improved this contribution. 


\section{References}

Allmendinger, R.W., 1998. Inverse and forward numerical modeling of trishear faultpropagation folds. Tectonics 17, 640-656.

Allmendinger, R.W., Cardozo, N., Fisher, D.M., 2012. Structural Geology Algorithms: Vectors and Tensors. Cambridge University Press.

Bêche, M., Kirkwood, D., Jardin, A., Desaulniers, E., Saucier, D., Roure, F., 2007. 2D Depth Seismic Imaging in the Gaspé Belt , a Structurally Complex Fold and Thrust Belt in the Northern Appalachians, Québec, Canada, in: Thrust Belts and Foreland Basins. 75-90.

Bond, C.E., 2015. Uncertainty in structural interpretation: Lessons to be learnt. Journal of Structural Geology 74, 185-200. doi:10.1016/j.jsg.2015.03.003

Bond, C.E., Gibbs, A.D., Shipton, Z.K., Jones, S., 2007. What do you think this is? 'Conceptual uncertainty' in geoscience interpretation. GSA Today 17, 4. doi:10.1130/GSAT01711A.1

Bond, C.E., Lunn, R.J., Shipton, Z.K., Lunn, A.D., 2012. What makes an expert effective at interpreting seismic images? Geology 40, 75-78. doi:10.1130/G32375.1

Brandes, C., Tanner, D.C., 2013. Fault-related folding: A review of kinematic models and their application. Earth-Science Reviews 138, 352-370. doi:10.1016/j.earscirev.2014.06.008

Brown, A.R., Denham, L.R., Agarwal, D.K., 2004. Depth Conversion and Depth Imaging, in: AAPG Memoir 42 and SEG Investigations in Geophysics, No. 9. 351394.

Butler, R.W.H., Paton, D.A., 2010. Evaluating lateral compaction in deepwater fold and thrust belts: How much are we missing from 'nature's sandbox'? GSA Today 20, 4-10. doi:10.1130/GSATG77A.1

Cardozo, N., Aanonsen, S., 2009. Optimized trishear inverse modeling. Journal of Structural Geology 31, 546-560. doi:10.1016/j.jsg.2009.03.003

Cardozo, N., Brandenburg, J.P., 2014. Kinematic modeling of folding above listric propagating thrusts. Journal of Structural Geology 60, 1-12. doi:10.1016/j.jsg.2013.12.004

Cardozo, N., Jackson, C. A.-L., Whipp, P.S., 2011. Determining the uniqueness of best-fit trishear models. Journal of Structural Geology 33, 1063-1078. doi:10.1016/j.jsg.2011.04.001

Cobbold, P.R., Clarke, B.J., Loseth, H., 2009. Structural consequences of fluid overpressure and seepage forces in the outer thrust belt of the Niger Delta. Petroleum Geoscience 15, 3-15. doi:10.1144/1354-079309-784 
Eichelberger, N.W., Hughes, A.N., Nunns, A.G., 2015. Combining multiple quantitative structural analysis techniques to create robust structural interpretations. Interpretation 3, SAA89-SAA104.

Epard, J.-L, Groshong, R.H., Jr., 1993. Excess area and depth to detachment. AAPG Bulletin 77, 1291-1302.

Erslev, E.A., 1991. Trishear fault-propagation folding. Geology 19, 617-620. doi:10.1130/0091-7613(1991)019<0617

Etris, E.L., Crabtree, N.J., Dewar, J., 2001. True Depth Conversion: More Than a Pretty Picture. CSEG Recorder 26, 11-22.

Fagin, S., 1996. The fault shadow problem: Its nature and elimination. The Leading Edge 1005-1013. doi:10.1190/1.1437403

Gibbs, A.D., 1983. Balanced cross-section construction from seismic sections in areas of extensional tectonics. Journal of Structural Geology 5, 153-160.

Gray, S.H., Cheadle, S., Vestrum, R., Gittins, J., Zhu, T., Nanan, H., 2001. Using Advanced Seismic Imaging Tools to See the Invisible Beneath Foothills Structures. CSEG Recorder 27, 16-28.

Groshong, R.H., Jr., 2015. Quality control and risk assessment of seismic profiles using area-depth-strain analysis. Interpretation 3, SAA1-SAA15.

Groshong, R.H., Jr., Bond, C.E., Gibbs, A., Ratliff, R., Wiltschko, D. V., 2012a. Preface: Structural balancing at the start of the 21st century: 100 years since Chamberlin. Journal of Structural Geology 41, 1-5. doi:10.1016/j.jsg.2012.03.010

Groshong, R.H., Jr., Epard, J.-L., 1994. The role of strain in area-constant detachment folding. Journal of Structural Geology 16, 613-618. doi:10.1016/01918141(94)90113-9

Groshong, R.H., Jr., Withjack, M.O., Schlische, R.W., Hidayah, T.N., 2012b. Bed length does not remain constant during deformation: Recognition and why it matters. Journal of Structural Geology 41, 86-97. doi:10.1016/j.jsg.2012.02.009

Higgins, S., Clarke, B., Davies, R.J., Cartwright, J., 2009. Internal geometry and growth history of a thrust-related anticline in a deep water fold belt. Journal of Structural Geology 31, 1597-1611. doi:10.1016/j.jsg.2009.07.006

Higgins, S., Davies, R.J., Clarke, B., 2007. Antithetic fault linkages in a deep water fold and thrust belt. Journal of Structural Geology 29, 1900-1914. doi:10.1016/j.jsg.2007.09.004

Hughes, A.N., Shaw, J.H., 2014. Fault displacement-distance relationships as indicators of contractional fault-related folding style. AAPG Bulletin 98, 227-251. doi:10.1306/05311312006

Jardin, A., Chaker, R., Krzywiec, P., 2007. Understanding Seismic Propagation through Triangle Zones, in: Thrust Belts and Foreland Basins. 63-74. 
Kostenko, O. V., Naruk, S.J., Hack, W., Poupon, M., Meyer, H.-J., Mora-Glukstad, M., Anowai, C., Mordi, M., 2008. Structural evaluation of column-height controls at a toe-thrust discovery, deep-water Niger Delta. AAPG Bulletin 92, 1615-1638. doi:10.1306/08040808056

Pei, Y., Paton, D.A., Knipe, R.J., 2014. Defining a 3-dimensional trishear parameter space to understand the temporal evolution of fault propagation folds. Journal of Structural Geology 66, 284-297. doi:10.1016/j.jsg.2014.05.018

Polson, D., Curtis, A., 2010. Dynamics of uncertainty in geological interpretation. Journal of the Geological Society 167, 5-10. doi:10.1144/0016-76492009-055

Rowan, M.G., Kligfield, R., 1989. Cross section restoration and balancing as aid to seismic interpretation in extensional terranes. AAPG Bulletin 73, 955-966. doi:10.1306/44B4A2BC-170A-11D7-8645000102C1865D

Schlische, R.W., Groshong R.H., Jr., Withjack, M.O., Hidayah, T.N., 2014. Quantifying the geometry, displacements, and subresolution deformation in thrust-ramp anticlines with growth and erosion: From models to seismic-reflection profile. Journal of Structural Geology 69, 304-319. doi:10.1016/j.jsg.2014.07.012

Shaw, J.H., Connors, C.D., Suppe, J., 2005. Part 1: structural interpretation methods, in: Seismic Interpretation of Contractional Fault-Related Folds, An AAPG Seismic Atlas. 2-58.

Stewart, S.A., 2012. Interpretation validation on vertically exaggerated reflection seismic sections. Journal of Structural Geology 41, 38-46. doi:10.1016/j.jsg.2012.02.021

Torvela, T., Bond, C.E., 2011. Do experts use idealised structural models? Insights from a deepwater fold-thrust belt. Journal of Structural Geology 33, 51-58. doi:10.1016/j.jsg.2010.10.002

Veeken, P.C.H., Moerkerken, B. van, 2013. The seismic reflection method and its constraints, in: Veeken, P.C.H., Moerkerken, B. van (Eds.), Seismic Stratigraphy and Depositional Facies Models. Elsevier, pp. 15-104. doi:10.1016/B978-0-12411455-5.50002-4

Williams, G., Chapman, T., 1983. Strains developed in the hangingwalls of thrusts due to their slip/propagation rate: A dislocation model. Journal of Structural Geology 5, 563-571. doi:10.1016/0191-8141(83)90068-8

Zanella, A., Cobbold, P.R., Rojas, L., 2014. Beef veins and thrust detachments in Early Cretaceous source rocks, foothills of Magallanes-Austral Basin, southern Chile and Argentina: Structural evidence for fluid overpressure during hydrocarbon maturation. Marine and Petroleum Geology 55, 250-261. doi:10.1016/j.marpetgeo.2013.10.006 


\section{Figure captions}

Figure 1. Generalized workflow of structural model construction from seismic dataset.

Figure 2. Fold and thrust belts in deep water Niger Delta. (a) Regional tectonic map of offshore Niger Delta. Fault lines and shale diapir polygons are compiled from Higgins et al. (2009), Cobbold et al. (2009) and Morley et al. (2011) and presented on Shuttle Radar Topography Mission Digital Elevation Model. (b) Two-way travel time map of the fold-thrust structure in the deep water Niger Delta at pre-growth strata horizon "h3" (Higgins et al., 2009, their Fig. 6b). The location of the structure within the offshore Niger Delta has not been reported. Contour interval is $40 \mathrm{~ms}$. Solid red line with triangle marks indicates thrust faults. E-W solid line shows the location of the profile shown in Figure $3 \mathrm{a}$ and $3 \mathrm{~b}$, used for the seismic image interpretation. E-W dotted line marks the location of the profile in Figure 3c, used as the reference for the interpretation.

Figure 3. Seismic time profile of the fold-thrust structure in the deep water Niger Delta from Higgins et al. (2009). Profiles are displayed with approximately no vertical exaggeration assuming a constant seismic velocity of $2.0 \mathrm{~km} / \mathrm{s}$. Profile locations are shown in Figure 2. (a) Uninterpreted seismic time profile of Higgins et al. (2009, their

Fig. 15a). (b) Structural interpretation of seismic profile in Figure 3a. Solid lines are interpretations made in this study with reference to the original Higgins et al. (2009) interpretation on the adjacent profile shown in Figure 3c. Dash line is inferred east- 
dipping thrust based on Higgins et al. (2009). Red arrow along left side of the section shows detachment interpreted on the seismic image. (c) Seismic time profile located c. $1 \mathrm{~km}$ south of the profile in Figure 3a with Higgins et al. (2009) interpretation (their Fig. 7c and 7c2), which was the reference for our seismic interpretation.

Figure 4. Comparison of the Higgins et al. (2009) depth-profile and time-based interpretation made in this study. (a) Depth-converted interpretation of Higgins et al. (2009, their Fig. 15b), without vertical exaggeration. (b) Seismic interpretation in this study (equivalent to the interpretation in Fig. 3b). No vertical exaggeration, assuming the average seismic velocity of $2.0 \mathrm{~km} / \mathrm{s}$.

Figure 5. Velocity model frameworks for (a) Velocity Model 1, (b) Velocity Model 2 and (c) Velocity Model 3. Upper panel is structural framework of velocity model with velocity layer index whose parameters are shown in Table 1. Lower panel is schematic plot of interval velocity against depth.

Figure 6. Average velocity profiles for (a) Velocity Model 1, (b) Velocity Model 2 and (c) Velocity Model 3 with overlay of seismic time interpretation. All profiles are displayed without vertical exaggeration, assuming the average seismic velocity of 2.0 $\mathrm{km} / \mathrm{s}$. 
Figure 7. Seismic profiles and interpretations depth-converted using (a) Velocity Model 1, (b) Velocity Model 2 and (c) Velocity Model 3 with measured dip angle of the main thrust and the back-limb. Profiles are displayed without vertical exaggeration. Red arrow along left side of the profile shows interpreted detachment depth.

Figure 8. Difference in structural geometry of depth-converted interpretations. (a) Terminology for geometrical measurement. $L$ is bed length. $h$ is structural height measured from the top of the anticline to the base of the syncline. $D$ is fault displacement for a marker horizon along the fault, whereas $d$ is distance measured from the fault cut-off of the lowest marker horizon in the footwall. $T_{V}$ is vertical thickness between marker horizons. (b) Average vertical thickness between horizons. (c). Structural height. (d) Bed length. (e) Fault displacement-distance profile for the main thrust. T denotes the fault tip interpreted from the seismic profile. White circle with dashed line represents measurements for depth-profile of Velocity Model 1, whereas grey circle with grey solid line is for that of Velocity Model 2 and black circle with black solid line is for that of Velocity Model 3.

Figure 9. Comparison of the depth-converted interpretation in this study and the equivalent depth interpretation from Higgins et al. (2009, their Fig. 15b). (a) Velocity Model 1, (b) Velocity Model 2 and (c) Velocity Model 3. Upper panel shows the depthconverted interpretation in this study (solid lines) with that of Higgins et al. (2009) (dash lines), at no vertical exaggeration display. Lower panel is cross-plot of depths measured for depth-converted horizons in this study and from Higgins et al. (2009) 
depth interpretation. Closer $\mathrm{R}^{2}$ to 1 indicates the goodness of fit between both depth interpretations.

Figure 10. Restoration and forward model using combination of trishear faultpropagation-folding and detachment fold algorithms for the depth-profile converted using Velocity Model 1 (left), Velocity Model 2 (middle) and Velocity Model 3 (right). No vertical exaggeration. (a) Final forward model (black lines) with the depth interpretation (colored lines) superimposed on the depth-converted seismic image. Trishear model parameters used are shown within rectangles at bottom of the profile. (b) Restored beds of the pre-growth section (dashed lines) using trishear faultpropagation-folding presented with detachment fold model (grey lines). Dotted black lines indicate hinges for the detachment fold model. Detachment fold parameters used are shown within rectangles at bottom of the profile. (c) Restored beds of pre-growth strata (dashed lines) using trishear fault-propagation-folding and detachment fold, with templates of retro-deformed beds (grey lines).

Figure 11. Best-fit trishear models determined by inverse trishear modelling for horizon h5 in the depth-profile of Velocity Model 1 (left), Velocity Model 2 (middle) and Velocity Model 3 (right). Profiles are displayed without vertical exaggeration. (a) The lowest $f_{o b j}$ model (black) superimposed on the seismic reflection image and the depth interpretation (colored). Parameters of the trishear models for each depth-profile are shown within rectangles at bottom. (b) Low fobj $(<0.3)$ models for pre-growth section (grey) compared to the depth-converted interpretation (colored). (c) Restored 
geometries of the models (grey). (d) Model parameter distributions of the models. Vertical dash line is the model parameters for the lowest $f_{\text {obj }}$ model. Grey bar shows histogram of trishear models accompanied by a thrust stopping propagation up to horizon h9, whereas white bar is for models associated with unreliable thrust propagating above h9. Number of total low $\mathrm{f}_{\mathrm{obj}}$ models $(\mathrm{N})$ and that of geologically consistent low fobj models (in parentheses) are shown in upper right. Asterisks mark the model parameters predicted through the manual restoration and forward modelling.

Figure 12. Excess Area-Depth relationship for the depth-converted interpretation. Depth interpretation converted using (a) Velocity Model 1, (b) Velocity Model 2, and (c) Velocity Model 3, superimposed on seismic profile. LPS stands for layer-parallel strain which is calculated from predicted displacement on area-depth graph and observed bed length for each horizon on the seismic profile. Horizontal dash line represents detachment level predicted from area-depth graph. Red arrow shown along left side of section is detachment observed on depth-converted seismic profile. White triangle at the top centre of the section indicates the location where depths for excess area are measured on a vertical line for ADS analysis. Each excess area diagram (df) is shown alongside the depth-converted section (a-c). Area-depth points are labelled with horizon name and displacement (D) in kilometres. $R^{2}$ is goodness of linear fit for the area-depth points in the pre-growth section.

Figure 13. Workflow for improving depth conversion and interpretation using feedbacks from structural validation techniques. 


\section{Table captions}

Table 1. Velocity parameters for the three velocity model scenarios. Structural frameworks outlining the velocity models are shown in Figure 5. .

Table 2. Model parameters for restoring and forward modelling of the depth-converted interpretation.

Table 3. Model parameters for inverse trishear modelling. 
Figure 1.

Task $\quad \underline{\text { Input }} \quad \underline{\text { Personnel }}$

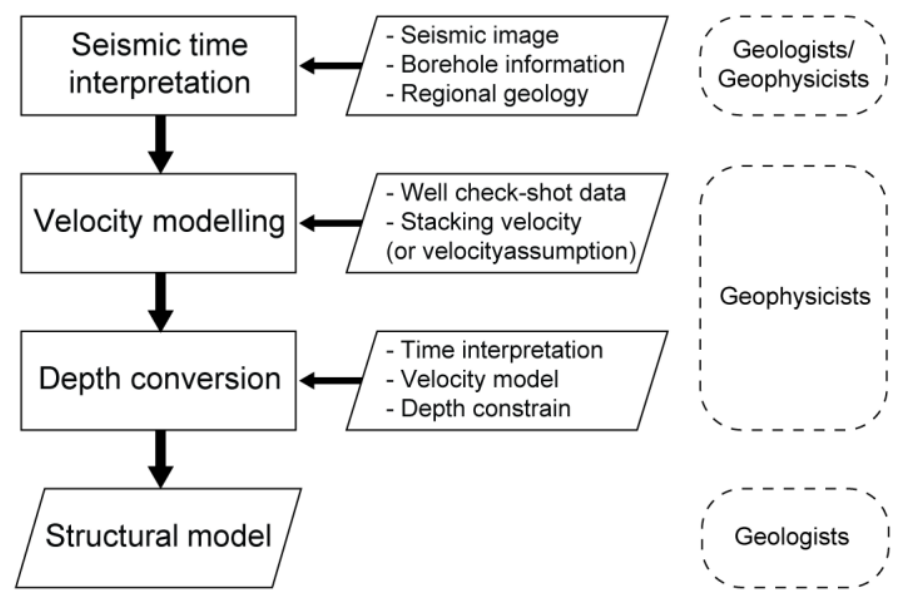


Figure 2.
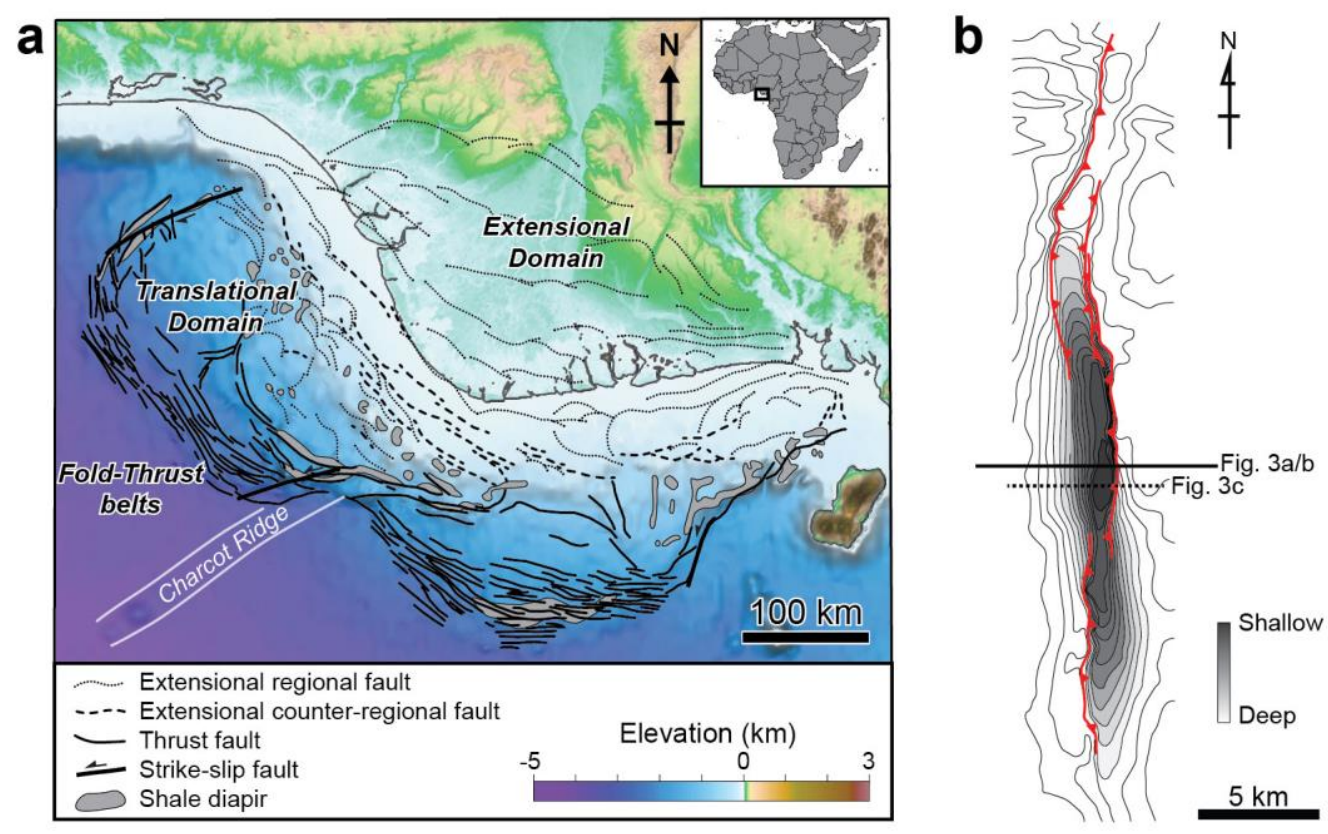
Figure 3.
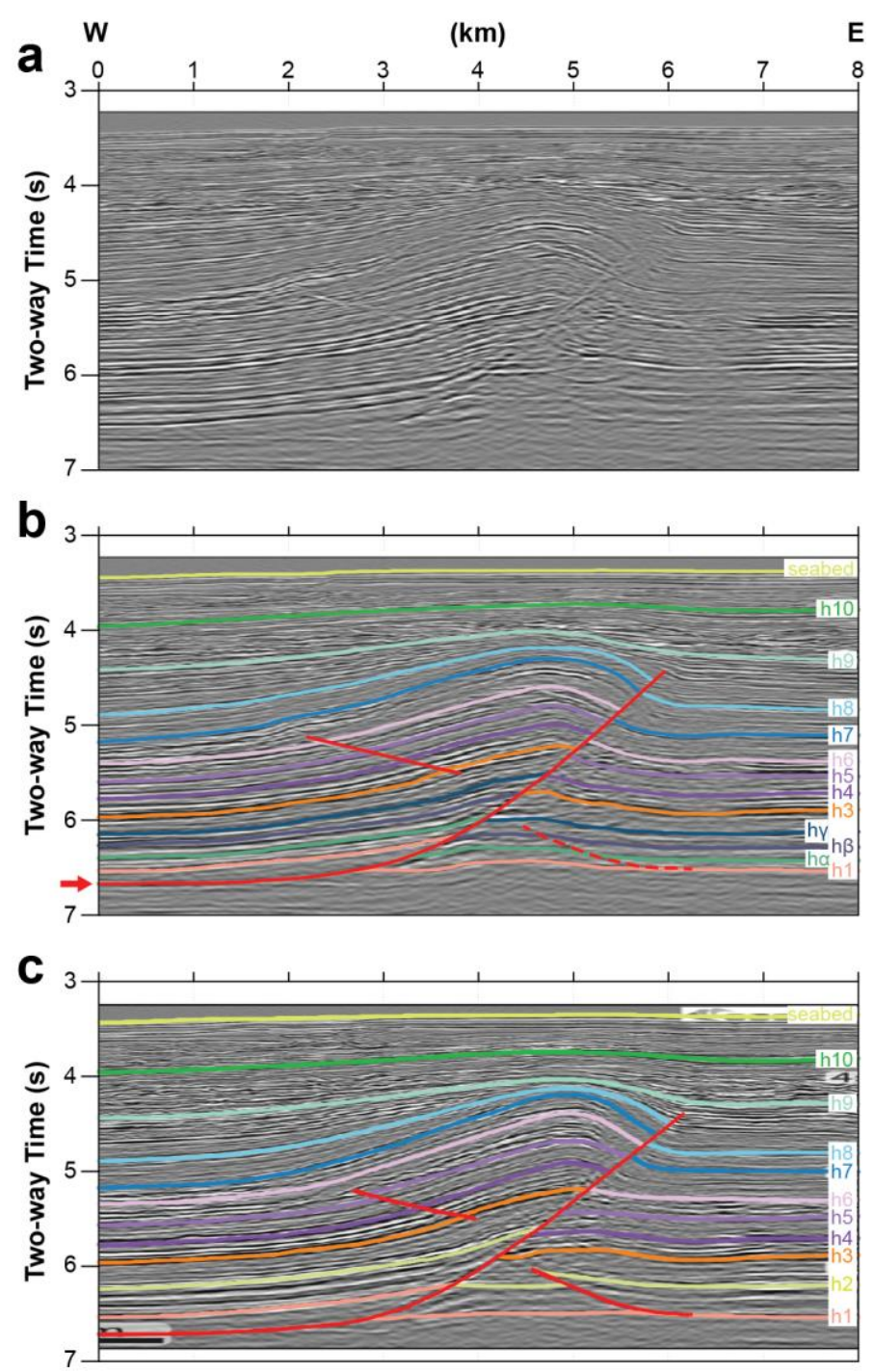
Figure 4.

a

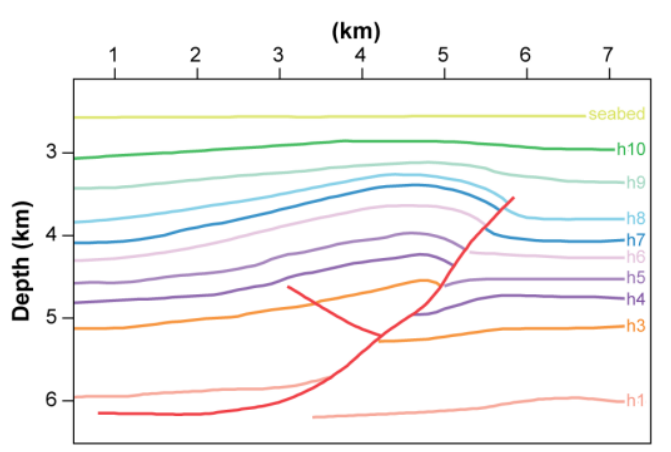

b

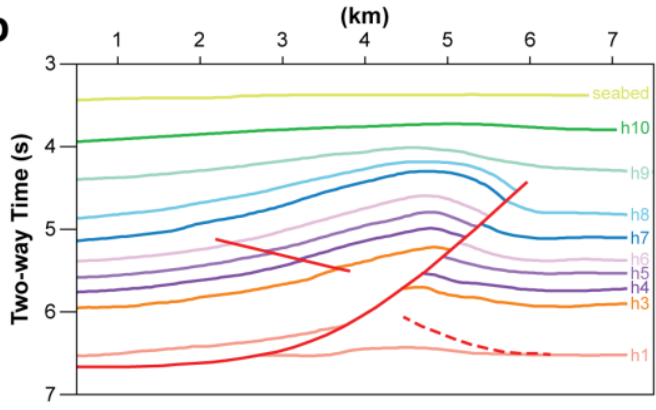


Figure 5.
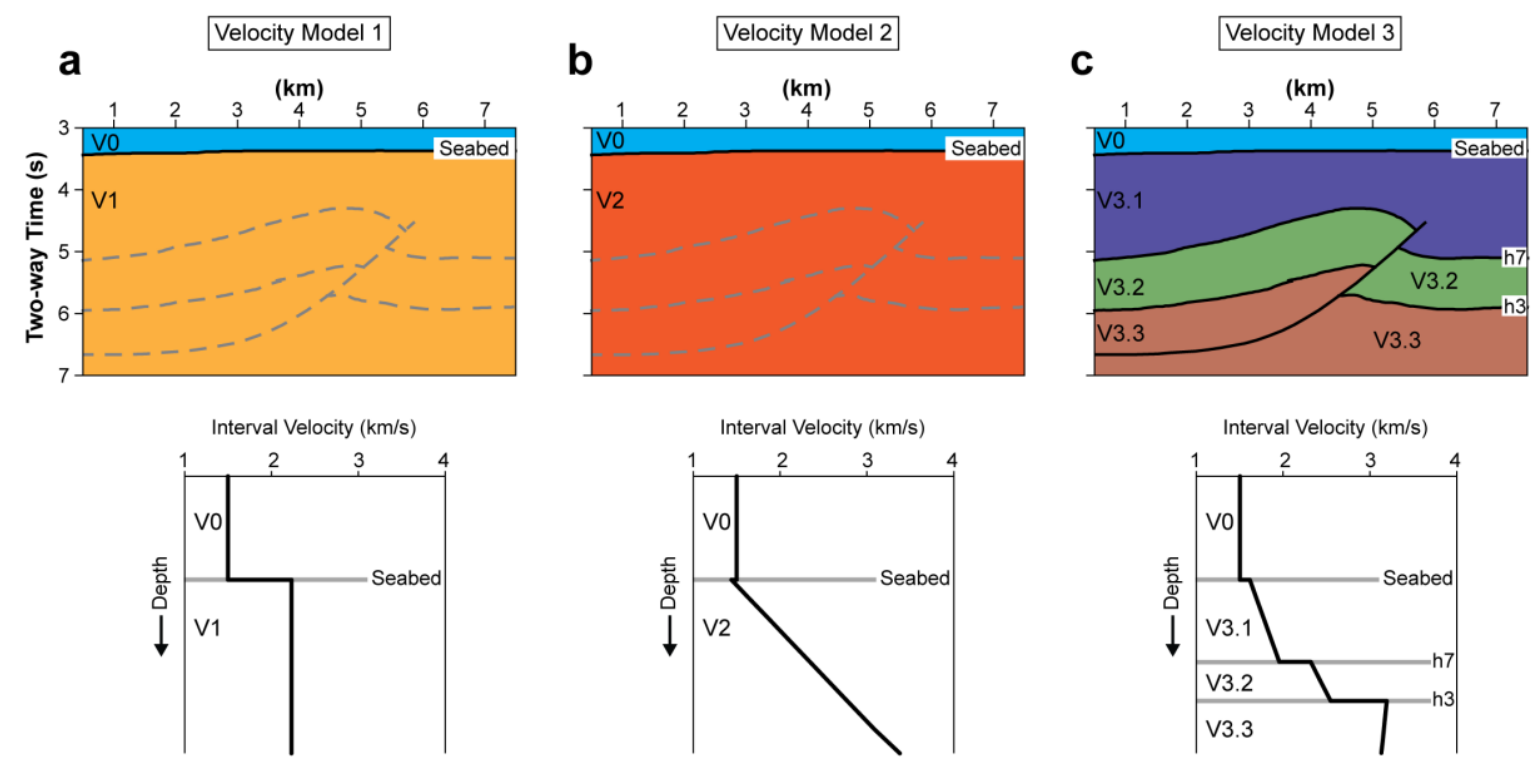
Figure 6.

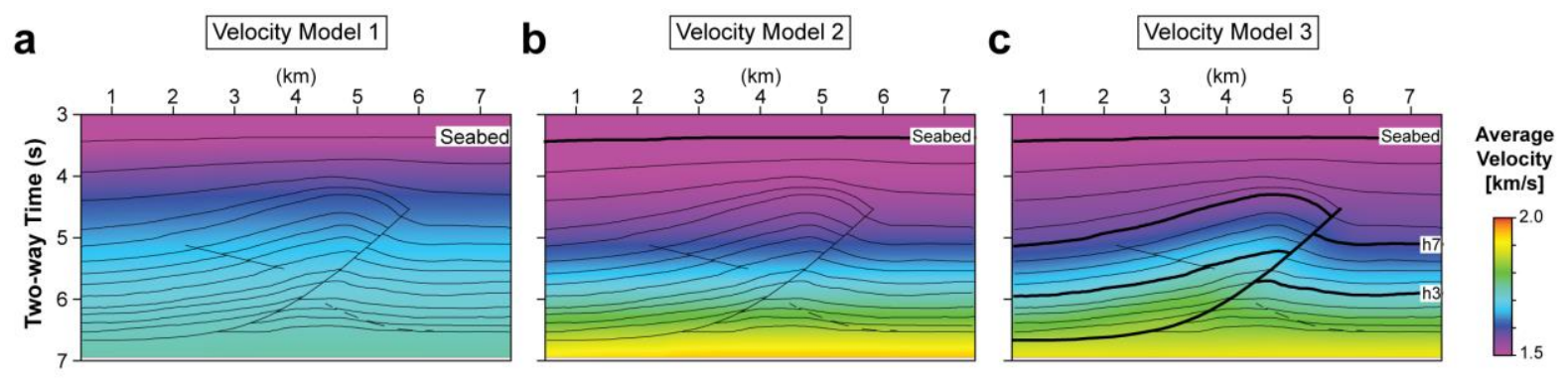


Figure 7.

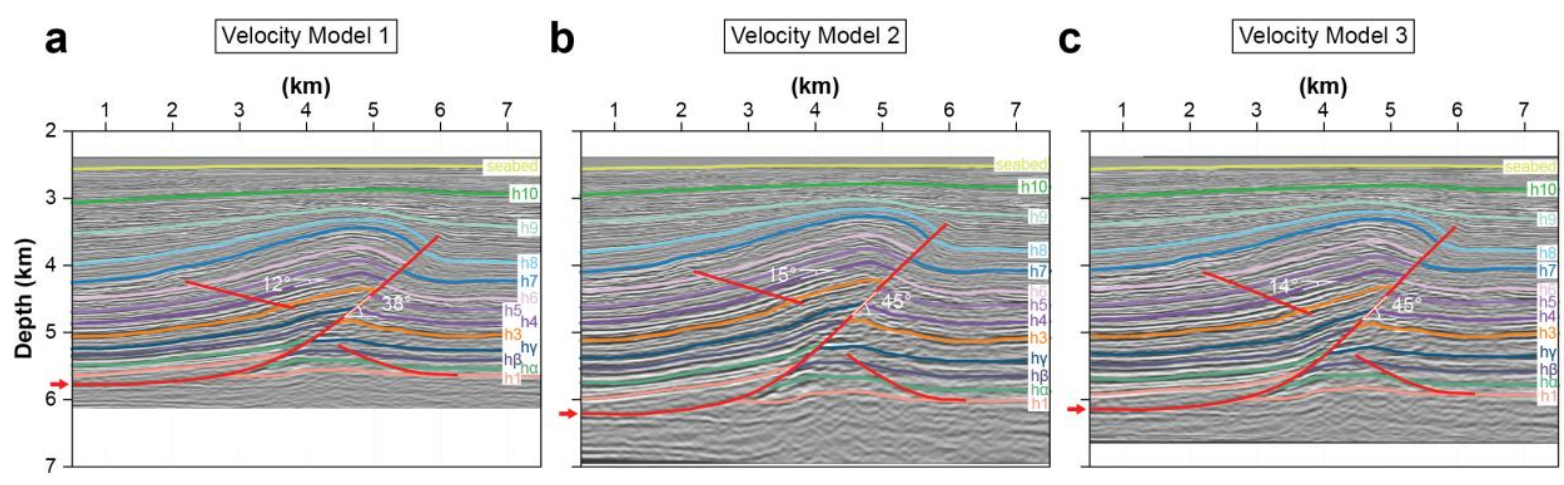


Figure 8.

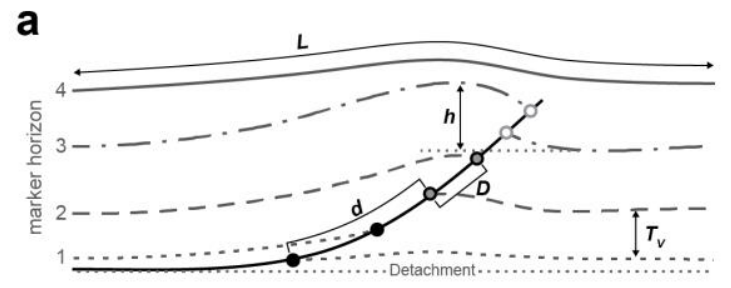

e
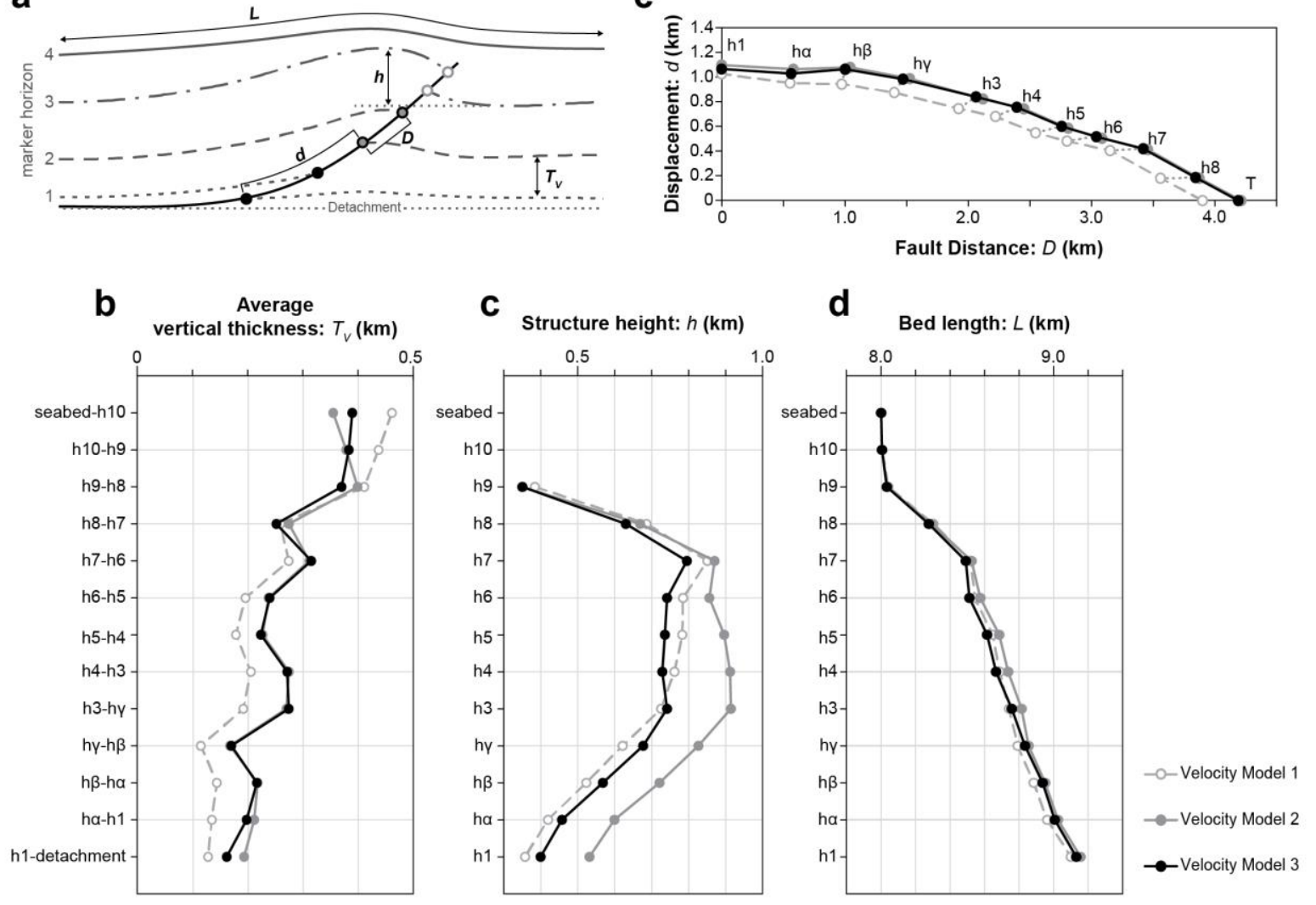
Figure 9.

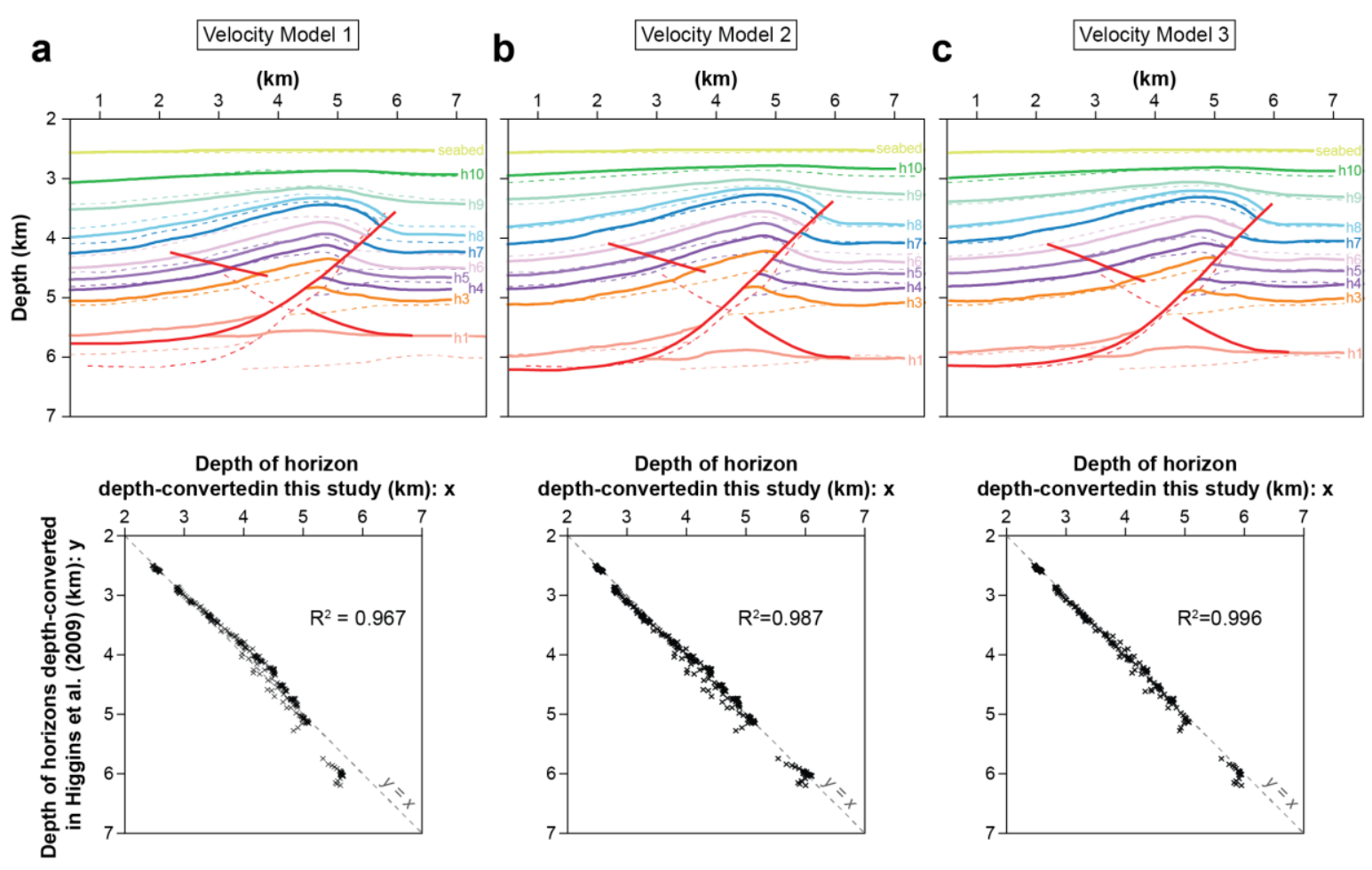


Figure 10.
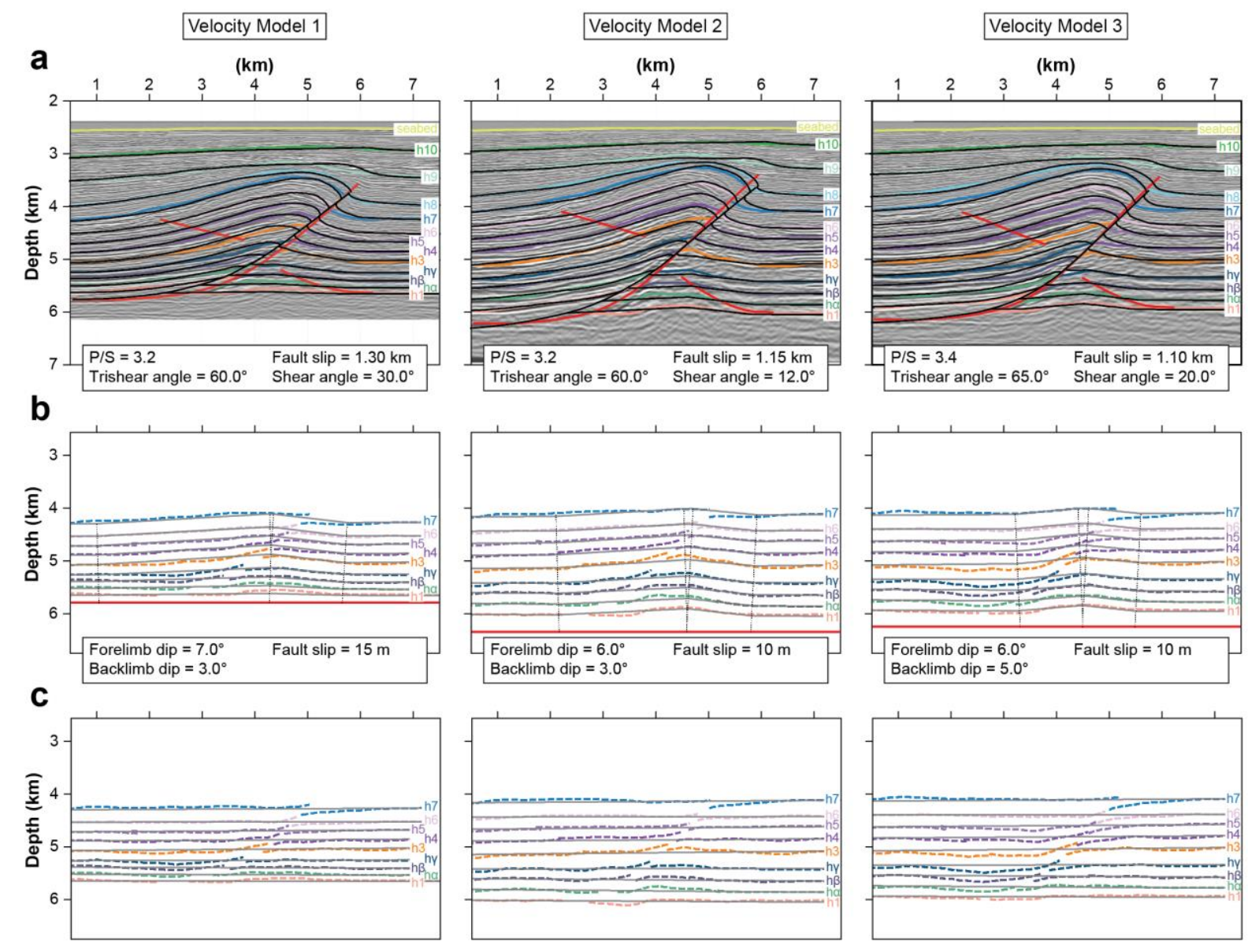
Figure 11.
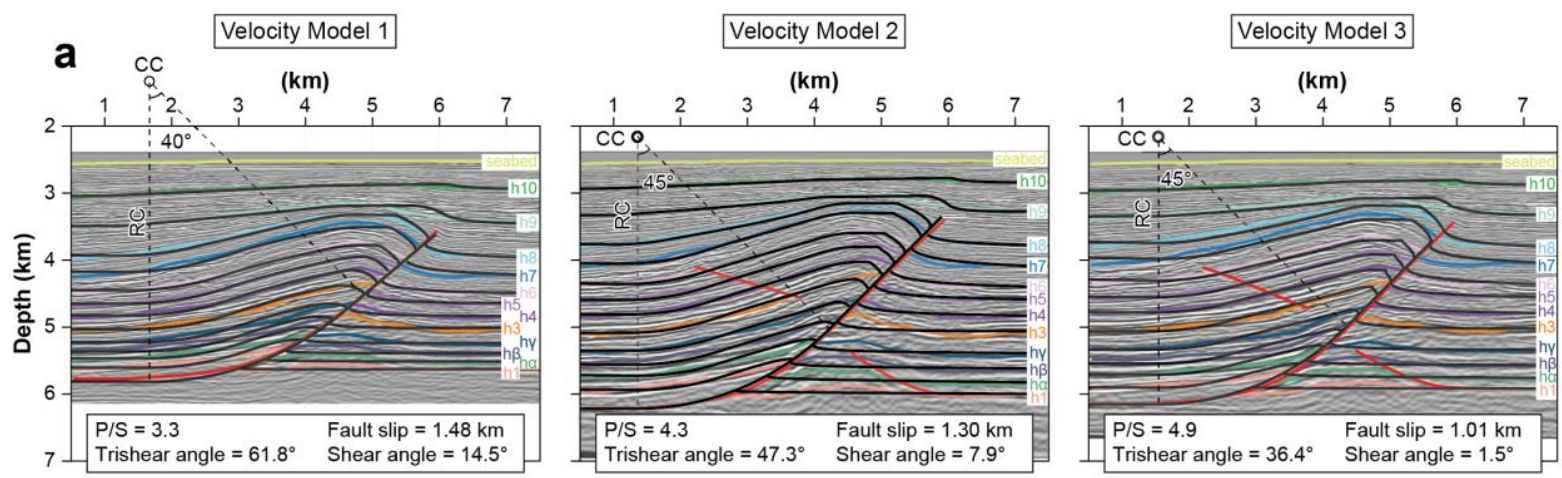

\section{b}
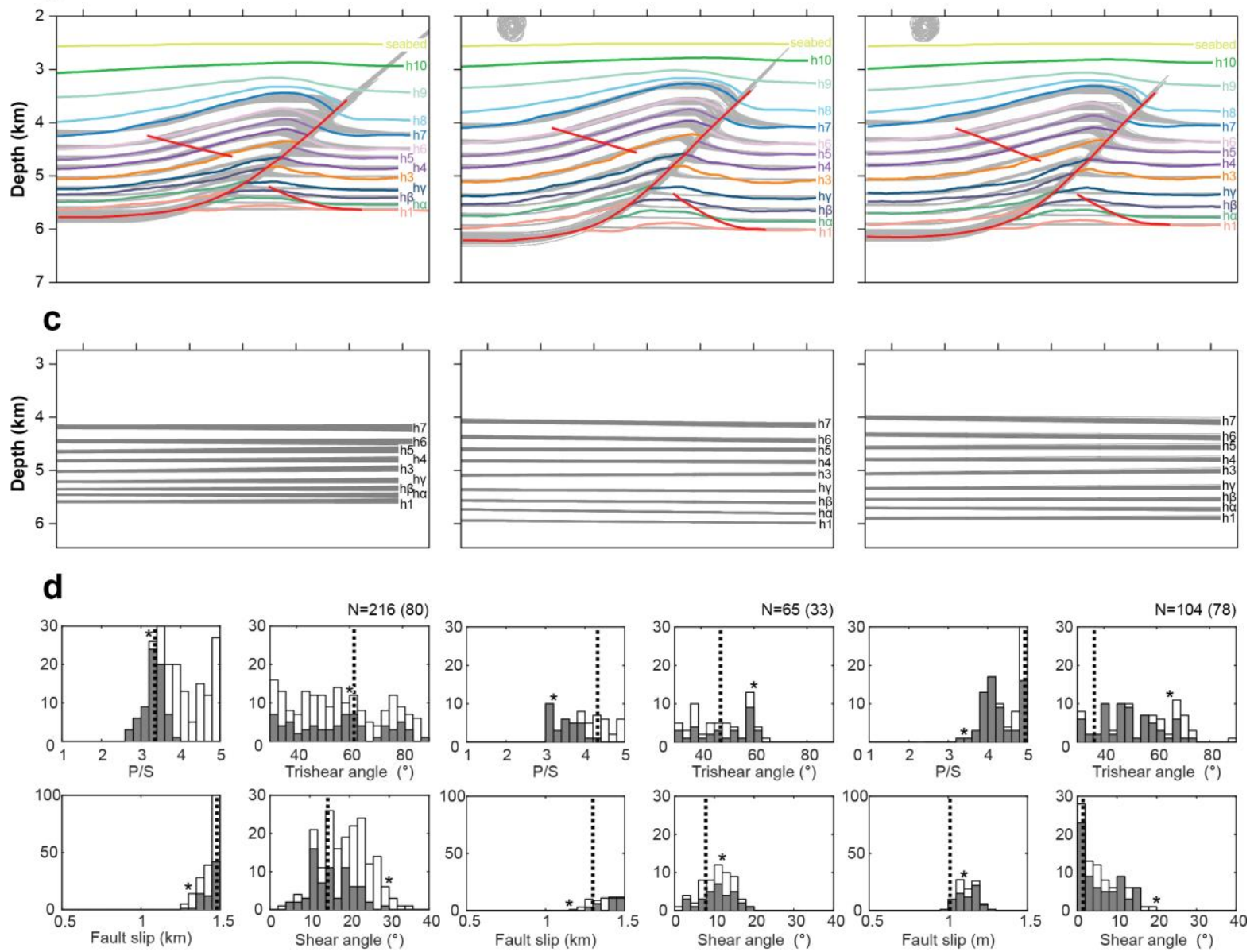
Figure 12.
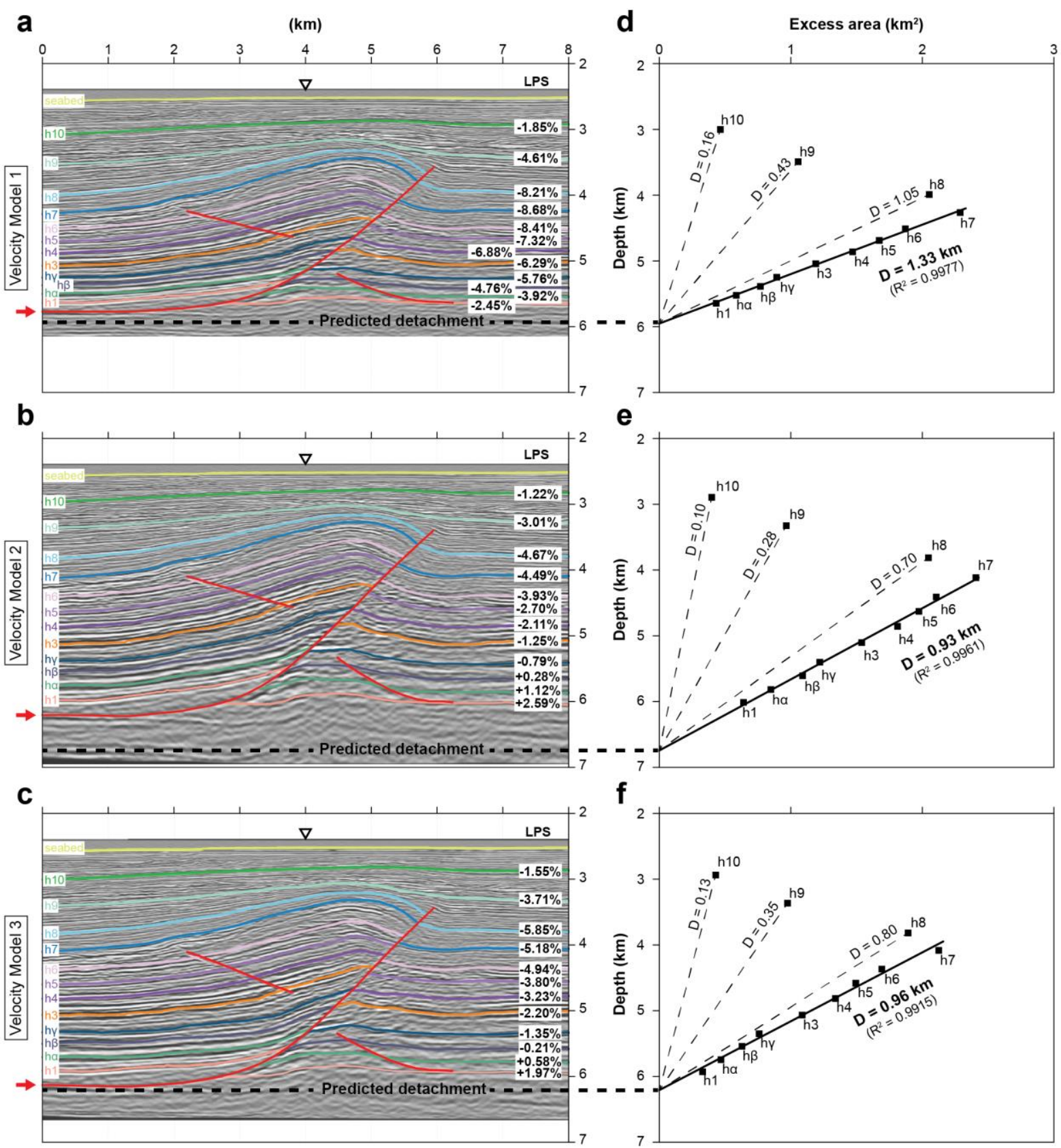
Figure 13.

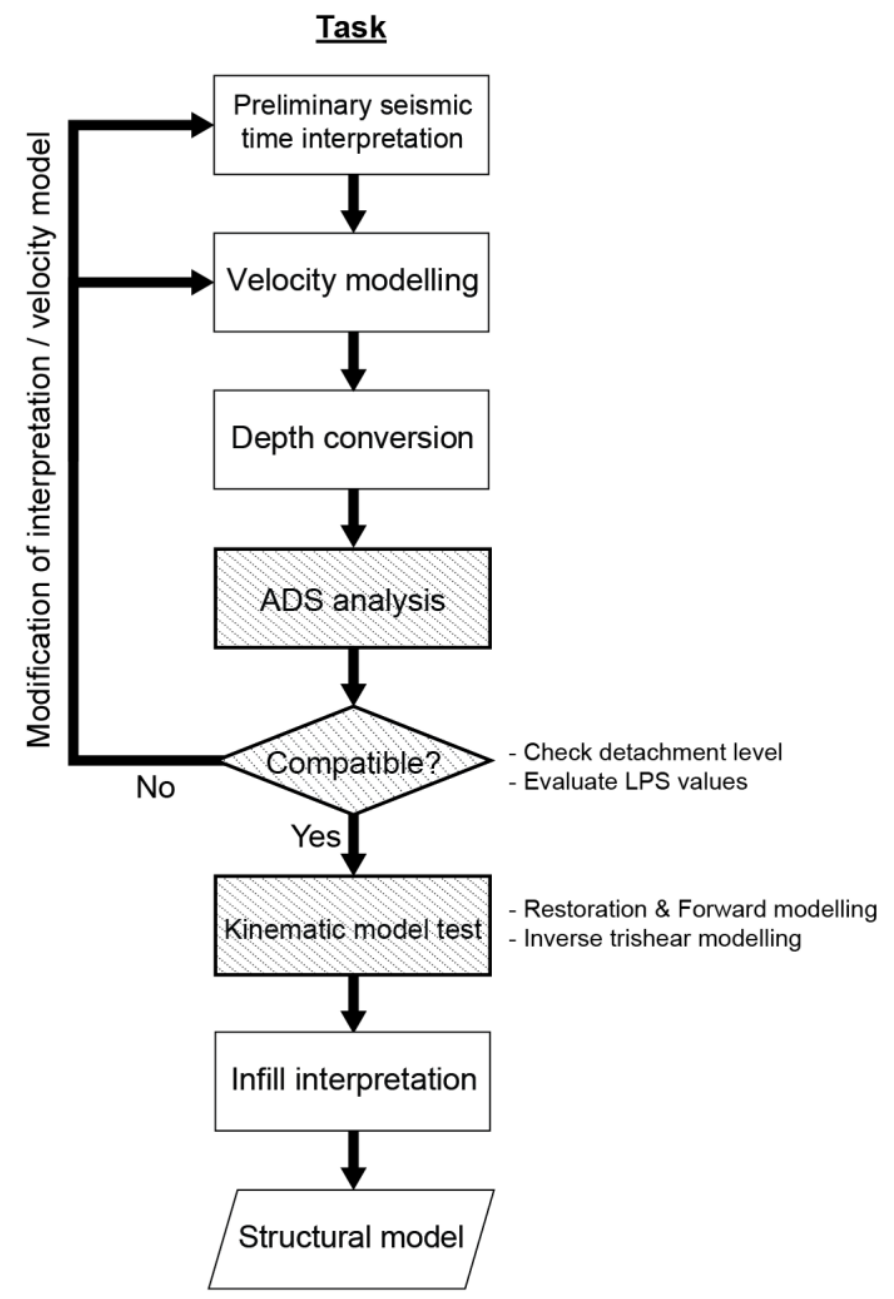


Table 1.

\begin{tabular}{ccc}
\hline $\begin{array}{c}\text { Velocity } \\
\text { indexes }\end{array}$ & $\begin{array}{c}\text { Initial velocity } \\
(\mathrm{km} / \mathrm{s})\end{array}$ & $\begin{array}{c}\text { Velocity } \\
\text { gradient }\left(\mathrm{s}^{-1}\right)\end{array}$ \\
\hline V0 & 1.5 & 0 \\
V1 & 2.0 & 0 \\
V2 & 1.4 & 0.53 \\
V3.1 & 1.6 & 0.19 \\
V3.2 & 2.3 & 0.31 \\
V3.3 & 3.2 & -0.12 \\
\hline
\end{tabular}

Table 2.

\begin{tabular}{lllccc}
\hline Kinematic model & Model parameter & Unit & Velocity Model 1 & Velocity Model 2 & Velocity Model 3 \\
\hline Trishear fault- & Slip $\quad \mathrm{h} 10$ & $\mathrm{~km}$ & 0.20 & 0.15 & 0.15 \\
propagation folding & $\mathrm{h9}$ & $\mathrm{km}$ & 0.60 & 0.35 & 0.40 \\
& h8 & $\mathrm{km}$ & 1.30 & 0.95 & 0.95 \\
& below h7 & $\mathrm{km}$ & 1.30 & 1.15 & 65 \\
& Trishear angle & $\mathrm{deg}$ & 60 & 60 & 3.4 \\
& P/S ratio & - & 3.2 & 3.2 & 20 \\
\hline & Shear angle & deg & 30 & 12 & 0.01 \\
\hline \multirow{2}{*}{ Detachment fold } & Slip (below h7 only) & $\mathrm{km}$ & 0.015 & 0.01 & 6.0 \\
& Forelimb dip & $\mathrm{deg}$ & 7.0 & 6.0 & 5.0 \\
\hline
\end{tabular}

Table 3.

\begin{tabular}{lcccccccccc}
\hline \multirow{2}{*}{ Model parameter } & \multirow{2}{*}{ Unit } & \multicolumn{3}{c}{ Velocity Model 1} & \multicolumn{3}{c}{ Velocity Model 2 } & \multicolumn{3}{c}{ Velocity Model 3 } \\
& & Lower & Initial & Upper & Lower & Initial & Upper & Lower & Initial & Upper \\
\hline Center of curvature (CC): $\mathrm{x}$ & $\mathrm{km}$ & 1.65 & 1.75 & 1.85 & 1.35 & 1.45 & 1.55 & 1.53 & 1.63 & 1.73 \\
Center of curvature $(\mathrm{CC}): \mathrm{y}$ & $\mathrm{km}$ & -1.35 & -1.25 & -1.15 & -2.30 & -2.20 & -2.10 & -2.33 & -2.23 & -2.13 \\
Maximum central angle $\left(\theta_{\max }\right)$ & $\mathrm{deg}$ & - & 40 & - & - & 45 & - & - & 45 & - \\
Radius of curvature $(\mathrm{RC})$ & $\mathrm{km}$ & 4.4 & 4.5 & 4.6 & 3.9 & 4.0 & 4.1 & 3.8 & 3.9 & 4.0 \\
P/S ratio & - & 1 & 3 & 5 & 1 & 3 & 5 & 1 & 3 & 5 \\
Trishear angle & $\mathrm{deg}$ & 30 & 60 & 90 & 30 & 60 & 90 & 30 & 60 & 90 \\
Fault slip & $\mathrm{km}$ & 0.5 & 1.0 & 1.5 & 0.5 & 1.0 & 1.5 & 0.5 & 1.0 & 1.5 \\
Shear angle & $\mathrm{deg}$ & 0 & 20 & 40 & 0 & 20 & 40 & 0 & 20 & 40 \\
\hline
\end{tabular}

